\title{
An assessment of the Arctic Ocean in a suite of interannual CORE-II simulations. Part II: Liquid freshwater
}

Qiang Wang ${ }^{\mathrm{a}, *}$, Mehmet Ilicak ${ }^{\mathrm{b}}$, Rüdiger Gerdes ${ }^{\mathrm{a}}$, Helge Drange ${ }^{\mathrm{c}}$, Yevgeny Aksenov $^{\mathrm{d}}$, David A Bailey ${ }^{\mathrm{e}}$, Mats Bentsen ${ }^{\mathrm{b}}$, Arne Biastoch ${ }^{\mathrm{f}}$, Alexandra Bozec ${ }^{\mathrm{g}}$, Claus Böning ${ }^{\mathrm{f}}$, Christophe Cassou ${ }^{\mathrm{h}}$, Eric Chassignet ${ }^{\mathrm{g}}$, Andrew C. Coward ${ }^{\mathrm{d}}$, Beth Curry ${ }^{\mathrm{i}}$, Gokhan Danabasoglu ${ }^{\mathrm{e}}$, Sergey Danilov ${ }^{\mathrm{a}}$, Elodie Fernandez ${ }^{\mathrm{h}}$, Pier Giuseppe Fogli ${ }^{\mathrm{j}}$, Yosuke Fujii ${ }^{\mathrm{k}}$, Stephen M. Griffies ${ }^{\mathrm{l}}$, Doroteaciro Iovino ${ }^{\mathrm{j}}$, Alexandra Jahn ${ }^{\mathrm{e}, \mathrm{m}}$, Thomas Jung, ${ }^{\mathrm{a}, \mathrm{n}}$, William

G. Large ${ }^{\mathrm{e}}$, Craig Lee ${ }^{\mathrm{i}}$, Camille Lique, ${ }^{\mathrm{o}, \mathrm{p}}$, Jianhua Lu ${ }^{\mathrm{g}}$, Simona Masina ${ }^{\mathrm{j}}$, A.J. George Nurser $^{\mathrm{d}}$, Benjamin Rabe ${ }^{\mathrm{a}}$, Christina Roth ${ }^{\mathrm{f}}$, David Salas y Mélia ${ }^{\mathrm{q}}$, Bonita L. Samuels ${ }^{1}$, Paul Spence ${ }^{\mathrm{r}, \mathrm{s}}$, Hiroyuki Tsujinok ${ }^{\mathrm{k}}$, Sophie Valcke ${ }^{\mathrm{h}}$, Aurore Voldoire ${ }^{\mathrm{q}}$, Xuezhu Wang ${ }^{\mathrm{a}}$, Steve G. Yeager

${ }^{a}$ Alfred Wegener Institute, Helmholtz Centre for Polar and Marine Research (AWI), Bremerhaven, Germany

${ }^{b}$ Uni Research Ltd., Bergen, Norway

${ }^{c}$ University of Bergen, Bergen, Norway

${ }^{d}$ National Oceanography Centre (NOC), Southampton, SO14 3ZH, UK

${ }^{e}$ National Center for Atmospheric Research (NCAR), Boulder, CO, USA

${ }^{f}$ GEOMAR Helmholtz Centre for Ocean Research, Kiel, Germany

${ }^{g}$ Center for Ocean-Atmospheric Prediction Studies (COAPS), Florida State University, Tallahassee, $F L, U S A$

${ }^{h}$ Centre Européen de Recherche et de Formation Avancée en Calcul Scientifique (CERFACS), Toulouse, France

${ }^{i}$ Applied Physics Laboratory, University of Washington, seattle, Washington, USA

${ }^{j}$ Centro Euro-Mediterraneo sui Cambiamenti Climatici (CMCC), Bologna, Italy

${ }^{k}$ Meteorological Research Institute (MRI), Japan Meteorological Agency, Tsukuba, Japan

${ }^{l}$ NOAA Geophysical Fluid Dynamics Laboratory (GFDL), Princeton, NJ, USA

${ }^{m}$ Department of Atmospheric and Oceanic Sciences and Institute of Arctic and Alpine Research, University of Colorado, Boulder, CO, USA

${ }^{n}$ Institute of Environmental Physics, University of Bremen, Bremen, Germany

${ }^{\circ}$ Department of Earth Sciences, University of Oxford, Oxford, UK

${ }^{p}$ Laboratoire de Physique des Océans, Ifremer, centre de Brest, Plouzané, France

${ }^{q}$ Centre National de Recherches Météorologiques (CNRM), Toulouse, France

${ }^{r}$ Climate Change Research Centre, University of New South Wales, Sydney, Australia

${ }^{s}$ ARC Centre of Excellence for Climate System Science, University of New South Wales, Sydney, Australia

\begin{abstract}
\footnotetext{
*Corresponding author

Email address: Qiang.Wang@awi.de (Qiang Wang)
}

The Arctic Ocean simulated in fourteen global ocean-sea ice models in the framework of the Coordinated Ocean-ice Reference Experiments, phase II (CORE-II) is analyzed in this study. The focus is on the Arctic liquid freshwater (FW) sources and freshwater 
content (FWC). The models agree on the interannual variability of liquid $\mathrm{FW}$ transport at the gateways where the ocean volume transport determines the FW transport variability. The variation of liquid FWC is induced by both the surface FW flux (associated with sea ice production) and lateral liquid FW transport, which are in phase when averaged on decadal time scales. The liquid FWC shows an increase starting from the mid-1990s, caused by the reduction of both sea ice formation and liquid FW export, with the former being more significant in most of the models. The mean state of the $\mathrm{FW}$ budget is less consistently simulated than the temporal variability. The model ensemble means of liquid FW transport through the Arctic gateways compare well with observations. On average, the models have too high mean FWC, weaker upward trends of FWC in the recent decade than the observation, and low consistency in the temporal variation of FWC spatial distribution, which needs to be further explored for the purpose of model development.

Keywords: Arctic Ocean, Freshwater, Sea ice, CORE II atmospheric forcing

\section{Contents}

\begin{tabular}{lll}
\hline 1 & Introduction & 3
\end{tabular}

1.1 Participating models . . . . . . . . . . . . . . . . . . . . . . 4

1.2 Model representation of the CAA $\ldots \ldots \ldots \ldots$

1.3 Model spin-up . . . . . . . . . . . . . . . . . . . . . . . . . . . . . . . 9

$\begin{array}{lll}2 & \text { Mean state } & 10\end{array}$

2.1 Liquid freshwater sources . . . . . . . . . . . . . . . . . . . . . 10

2.1 .1 Transport through gateways . . . . . . . . . . . . . . . . . . . . 10

2.1 .2 Surface freshwater budget $\ldots \ldots \ldots$. . . . . . . . . . . 15

10

2.2 Liquid freshwater content $\ldots \ldots \ldots \ldots$

$\begin{array}{lll}3 & \text { Interannual variability } & 18\end{array}$

3.1 Liquid freshwater sources $\ldots \ldots \ldots$. . . . . . . . . . . . . . . 18

3.1 .1 Transport through gateways . . . . . . . . . . . . . . 18

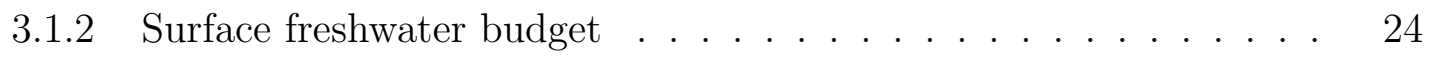

3.2 Liquid freshwater content . . . . . . . . . . . . . . 25 
3.2.1 $\quad$ FWC integrated over the Arctic Ocean . . . . . . . . . . . . . 25

$3.2 .2 \quad$ FWC spatial distribution . . . . . . . . . . . . . . . . . . . . 28

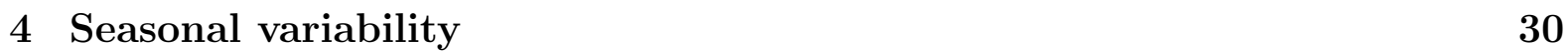

5 Summary on the model ensemble mean 34

\begin{tabular}{lll}
\hline 6 & Conclusion & 37
\end{tabular}

\begin{tabular}{|l|l}
\hline Appendix A. Definition of freshwater content and transport & 41
\end{tabular}

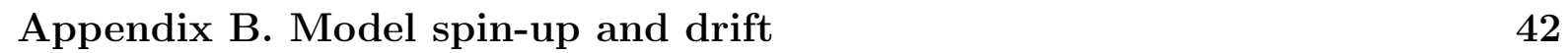

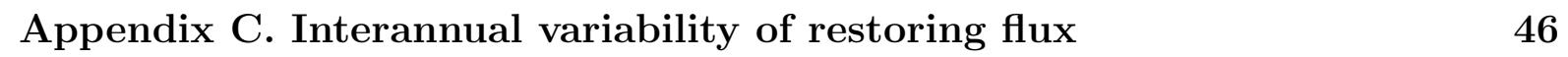

\begin{tabular}{ll}
\hline References & 49
\end{tabular}

\section{Introduction}

The Arctic Ocean is a large freshwater $(\mathrm{FW})$ reservoir of the climate system. It receives oceanic FW from the Pacific through Bering Strait, runoff from rivers and streams, and precipitation at the surface (Serreze et al., 2006; Dickson et al., 2007). FW in the Arctic Ocean exists in the solid form mainly as sea ice and in the liquid form located in

the upper ocean. Sea ice is exported to the North Atlantic mainly through Fram Strait, while the excess liquid FW is released from the Arctic Ocean through both Davis and Fram Straits. Due to the proximity to the deep water formation sites, the FW exported to the North Atlantic can influence the large scale ocean circulation (e.g., Aagaard et al., 1985; Goosse et al., 1997; Hakkinen, 1999; Wadley and Bigg, 2002; Jungclaus et al., 2005).

The liquid FW stored in the Arctic Ocean forms a strong halocline near the ocean surface, separating the warmer water below it from the upper mixed layer, sea ice and atmosphere. Therefore it is an important component of the Arctic climate system. The storage of liquid FW in the Arctic Ocean increases starting from about mid 1990s as shown by observations of hydrography (Proshutinsky et al., 2009; McPhee et al., 2009; 40 Rabe et al. 2011; Polyakov et al. 2013; Rabe et al., 2014) and sea surface height (SSH) (Giles et al., 2012). In the meantime the liquid FW export through Davis Strait has 
significantly declined in the period of 2004-2010 compared to 1987-1999 Curry et al. (2014)). If the large amount of FW currently stored in the Arctic Ocean is released to the North Atlantic, there might be strong impact on the large scale ocean circulation.

Faithfully simulating Arctic FW storage and export in numerical models is important for an adequate representation of the role played by the FW cycle in the climate system. However, numerical models show significant uncertainties in their simulated Arctic FW budget (Holland et al., 2007; Jahn et al., 2012). In this work we analyze and compare the Arctic FW budget simulated by fourteen ocean-ice models participating in the Coordinated Ocean-ice Reference Experiments, phase II (CORE-II) project. All the models are driven by the same atmospheric state, the CORE interannual forcing (Large and Yeager, 2009), and use the same (NCAR) bulk formulae (see the CORE-II protocol described by Griffies et al. (2012)). They are global ocean-ice models which have been used in different coupled climate models. We will discuss model consistency and spread by comparing to available observations, and identify issues that need to be addressed in future model development.

The focus of this paper is on the Arctic liquid FW budget. Arctic solid FW budget simulated by the CORE-II models is discussed in Wang et al. (2015). We will quantify both the liquid FW storage (defined as freshwater content, FWC) and the FW sources to get an insight into the mean state and variability of the Arctic liquid FW budget. The definition of FWC and FW fluxes is given in Appendix A. Note that we only study the simulated advective FW flux in this work, and the fluxes associated with subgrid scale parameterizations are not considered in our analysis.

\subsection{Participating models}

Data from fourteen CORE-II models are analyzed in this paper. The models are listed in Table 1, together with the names of the groups operating the models and the basic model configuration information. Most of the models use z-level (or $\mathrm{z}^{*}$ ) coordinates, except for three models with isopycnal or hybrid vertical grids (GOLD, FSU and Bergen). Among the participating models, ten models are with nominal $1^{\circ}$ horizontal resolution, three with $0.5^{\circ}$, and one with $0.25^{\circ}$. The resolution in $\mathrm{km}$ varies significantly in space and direction in the Arctic Ocean, so we can only give very approximate mean values. 
Table 1: Summary of the ocean and sea-ice models in alphabetical order according to the participating group name (first column). The table includes the name of the combined ocean-sea ice configuration (if any); the ocean model name and its version; the sea-ice model name and its version; vertical coordinate and number of layers/levels in parentheses; orientation of the horizontal grid with respect to the North Pole/Arctic; the number of horizontal grid cells (longitude, latitude); and the horizontal resolution (longitude, latitude). In MRI-A and MRI-F, the vertical levels shallower than $32 \mathrm{~m}$ follow the surface topography as in sigma-coordinate models. In AWI-FESOM, the total number of surface nodes is given, because it has an unstructured grid. The suite of participating models include 13 models analyzed in the CORE-II North Atlantic paper (Danabasoglu et al., 2014), and one $0.25^{\circ}$ fine horizontal grid spacing model (MOM0.25). FSU-HYCOM has a new model version for the CORE-II study (Danabasoglu et al. 2015), but it is not included in this work.

\begin{tabular}{|c|c|c|c|c|c|c|c|}
\hline Group & Configuration & Ocean model & Sea-ice model & Vertical & Orientation & Horiz. grid & Horiz. res. \\
\hline AWI & & FESOM 1.4 & FESIM 2 & $\mathrm{z}(46)$ & Displaced & 126000 & Nominal $1^{\circ}$ \\
\hline Bergen & NorESM-O & MICOM & CICE 4 & $\sigma_{2}(51+2)$ & Tripolar & $360 \times 384$ & Nominal $1^{\circ}$ \\
\hline CERFACS & ORCA1 & NEMO 3.2 & LIM 2 & $\mathrm{z}(42)$ & Tripolar & $360 \times 290$ & Nominal $1^{\circ}$ \\
\hline $\mathrm{CMCC}$ & ORCA1 & NEMO 3.3 & CICE 4 & z $(46)$ & Tripolar & $360 \times 290$ & Nominal $1^{\circ}$ \\
\hline CNRM & ORCA1 & NEMO 3.2 & Gelato 5 & $\mathrm{z}(42)$ & Tripolar & $360 \times 290$ & Nominal $1^{\circ}$ \\
\hline FSU & & HYCOM 2.2 & CSIM 5 & hybrid (32) & Displaced & $320 \times 384$ & Nominal $1^{\circ}$ \\
\hline GFDL-MOM & ESM2M-ocean-ice & MOM 4p1 & SIS1 & $z^{*}(50)$ & Tripolar & $360 \times 200$ & Nominal $1^{\circ}$ \\
\hline GFDL-UNSW & MOM0.25 & MOM 5 & SIS1 & $z^{*}(50)$ & Tripolar & $1440 \times 1070$ & Nominal $0.25^{\circ}$ \\
\hline GFDL-GOLD & ESM2G-ocean-ice & GOLD & SIS1 & $\sigma_{2}(59+4)$ & Tripolar & $360 \times 210$ & Nominal $1^{\circ}$ \\
\hline Kiel & ORCA05 & NEMO 3.1 .1 & LIM 2 & z $(46)$ & Tripolar & $722 \times 511$ & Nominal $0.5^{\circ}$ \\
\hline MRI-A & MRI assimilation & MOVE/MRI.COM 3 & MK89; CICE & $\mathrm{z}(50)$ & Tripolar & $360 \times 364$ & $1^{\mathrm{o}} \times 0.5^{\mathrm{o}}$ \\
\hline MRI-F & MRI free run & MRI.COM 3 & MK89; CICE & $\mathrm{z}(50)$ & Tripolar & $360 \times 364$ & $1^{\circ} \times 0.5^{\circ}$ \\
\hline NCAR & & POP 2 & CICE 4 & $\mathrm{z}(60)$ & Displaced & $320 \times 384$ & Nominal $1^{\circ}$ \\
\hline $\mathrm{NOC}$ & ORCA1 & NEMO 3.4 & LIM 2 & $\mathrm{z}(75)$ & Tripolar & $360 \times 290$ & Nominal $1^{\circ}$ \\
\hline
\end{tabular}


MOM0.25 has about $12 \mathrm{~km}$ horizontal resolution in the Arctic region, Kiel-ORCA05 and AWI-FESOM have about $24 \mathrm{~km}$, and the other models have about $48 \mathrm{~km}$.

One of the participating models, MRI-A, is a global ocean data assimilation system. It is the same as MRI-F except that temperature and salinity observational data are assimilated into the model ${ }^{1}$ Its results are compared to other models to provide information on whether the assimilation improves the key diagnostics of the Arctic Ocean. However, we do not include it for calculating model ensemble means.

As discussed by Griffies et al. (2009), ocean-ice models without a coupled active atmospheric model lack many of the feedbacks present in a fully coupled system. This necessitates restoring of model sea surface salinity (SSS) to observed climatological SSS in global ocean-ice models. In addition, SSS restoring helps to avoid unbounded local salinity trends that can occur in response to inaccuracies in precipitation. The strength of SSS restoring (defined by a piston velocity) is not specified in the CORE-II protocol and left to modellers to choose. The details of SSS restoring methods and piston velocity used in the models are described in Appendix C of Danabasoglu et al. (2014) $)^{2}$. It is worth mentioning here that SSS restoring is turned off under sea ice in Kiel-ORCA05. This simulation can serve as a reference for the discussion of the potential impact of SSS restoring on the Arctic liquid FW budget.

The Arctic Ocean exchanges FW with the Pacific and Atlantic Oceans through a few narrow straits, which cannot be explicitly resolved on coarse meshes. Each group developing climate models has its own way to treat them (for example, to widen the straits). The number of velocity grid cells across the narrow straits varies among the models, as shown in Table 2 .

We define the Arctic Ocean domain with the following four gateways: Bering Strait, Fram Strait, Davis Strait, and the Barents and Kara Seas northern boundary (BKN) (see Figure 1). Bering Strait is the only gateway connecting the Arctic Ocean with

\footnotetext{
${ }^{1}$ MRI-A was run for 70 years starting from model year 231 of the MRI-F integration. The first 10 years are treated as a spin-up phase and the last 60 years (associated with the period of CORE-II forcing) are used in this work.

${ }^{2}$ The actually used piston velocity ( $50 \mathrm{~m}$ over 100 days) in the CNRM model is stronger than that indicated in Danabasoglu et al. (2014).
} 


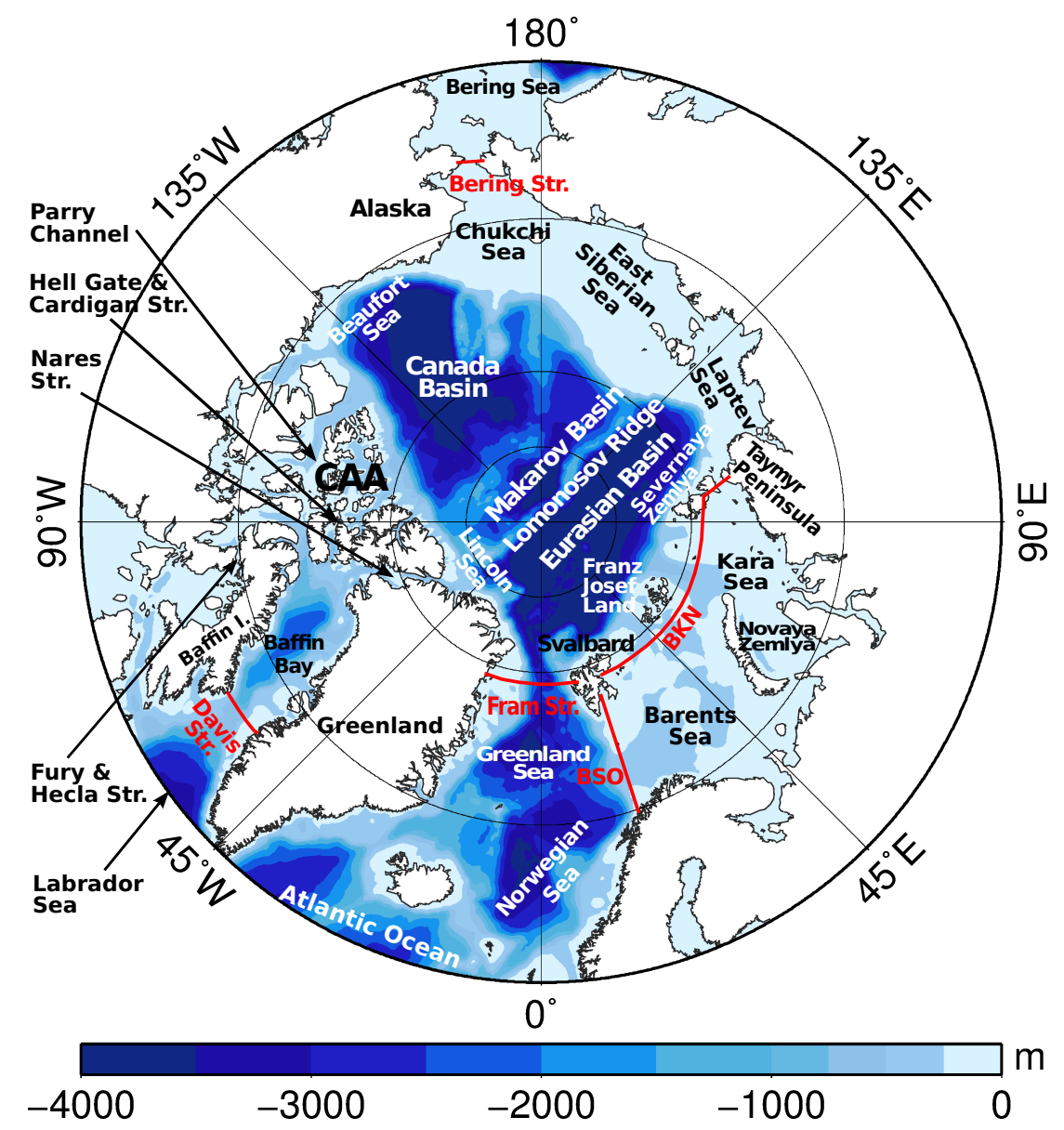

Figure 1: Arctic Ocean bottom topography [m]. The Arctic gateways discussed in the paper are shown with red lines. BSO stands for southern Barents Sea Opening, BKN for Barents/Kara Seas northern boundary, and CAA for Canadian Arctic Archipelago. The Arctic domain in this paper is defined by the gateways of Fram Strait, Davis Strait, Bering Strait, and BKN. 
Table 2: The number of grid cells with non-zero velocity across the major Canadian Arctic Archipelago (CAA) straits and Bering Strait. The number is counted at the narrowest location of each strait.

\begin{tabular}{lllllll}
\hline Group & Configuration & Ocean model & Parry Channel & Nares Strait & Hell Gate/Cardigan Strait & Bering Strait \\
\hline AWI & & FESOM 1.4 & 3 & 1 & 0 & 4 \\
Bergen & NorESM-O & MICOM & 2 & 1 & 1 & 2 \\
CERFACS & ORCA1 & NEMO 3.2 & 2 & 2 & 0 & 2 \\
CMCC & ORCA1 & NEMO 3.3 & 2 & 2 & 0 & 2 \\
CNRM & ORCA1 & NEMO 3.2 & 2 & 2 & 0 & 2 \\
FSU & & HYCOM 2.2 & 2 & 0 & 0 & 3 \\
GFDL-MOM & ESM2M-ocean-ice & MOM 4p1 & 1 & 1 & 0 & 1 \\
GFDL-UNSW & MOM0.25 & MOM 4p1 & 7 & 5 & 0 & 11 \\
GFDL-GOLD & ESM2G-ocean-ice & GOLD & 1 & 1 & 1 & 2 \\
Kiel & ORCA05 & NEMO 3.1.1 & 3 & 2 & 0 & 3 \\
MRI-A & & MOVE/MRI.COM 3 & 2 & 1 & 0 & 2 \\
MRI-F & & MRI.COM 3 & 2 & 1 & 0 & 2 \\
NCAR & & POP 2 & 1 & 1 & 0 & 1 \\
NOC & ORCA1 & NEMO 3.4 & 2 & 2 & 0 & 2 \\
\hline
\end{tabular}

the Pacific. In the Atlantic sector, the Arctic Ocean is connected with the Nordic Seas via Fram Strait, with the Labrador Sea via Davis Strait, and with the Barents/Kara Seas then the Nordic Seas via the BKN. We take Davis Strait rather than the Canadian Arctic Archipelago (CAA) as one of the Arctic Ocean boundaries for simplicity because the number of CAA passages connecting the Arctic Ocean and Baffin Bay is different among the models (Table 2).

Tables 1 and 2 show the basic model configurations, therein we list the models in the alphabetical order with respect to the names of the contributing groups. In all figures and other tables in this paper, we will group the models according to types of vertical coordinates and model origins, when possible. The five models based on NEMO are put closer, the same for the two MOM models with different horizontal resolution, the three isopycnal (and hybrid) models, and the free-run and assimilated MRI models.

\subsection{Model representation of the $C A A$}

Passages in the CAA connect the Arctic Ocean with Baffin Bay and Labrador Sea (Figure 1). They are very narrow and cannot be resolved with typical resolutions used in ocean climate models. Among the three major CAA straits, Parry Channel is the largest with a width of $52.3 \mathrm{~km}$ at its narrowest location; Nares Strait has a minimum width of $27.7 \mathrm{~km}$; and the Hell Gate/Cardigan Strait is only about $10 \mathrm{~km}$ in width (Melling, 2000). 
In practice, model developers have to decide how to represent these narrow straits in their models and take certain measures in order to obtain reasonable FW export, for example, by modifying channel width and depth. However, such treatment is seldom detailed in published papers. Most of the fourteen models used in this study have been set up a long time ago for the purpose of coupled climate model applications. It is not possible for us to retrieve enough information on how and why the CAA straits were handled from the model developers who designed the grids. We only list the number of non-zero velocity grid cells at the narrowest location of the three major CAA straits in Table2, Two models (Bergen and GFDL-GOLD) have all three main straits, one model (FSU-HYCOM) only has Parry Channel, and the other models have the two largest straits.

The information in Table 2 indicates that different modifications to the narrow straits have been done in the models. For example, the (approximately $10 \mathrm{~km}$ wide) Hell Gate/Cardigan Strait was certainly widened to have one cross-strait grid cell in the two models that keep it (Bergen and GFDL-GOLD). MRI-F and MRI-A have finer resolution than the four NEMO ORCA1 models, but they have only one cross-strait grid cell at the narrowest location in the Nares Strait, while the four NEMO ORCA1 models have two grid cells. MOM0.25 has the finest horizontal grid spacing (nominal $0.25^{\circ}$, about $12 \mathrm{~km}$ in this region) and at least five cross-strait grid cells across Nares Strait, which means that the strait has also been widened.

\subsection{Model spin-up}

The CORE-II atmospheric state used to drive the models covers 60 years from 1948 to 2007 (Large and Yeager, 2009). All models are run for 300 years, corresponding to 5 consecutive loops of the 60-year forcing period following the CORE-II protocol Griffies et al., 2012). In the CORE-II model intercomparison for the North Atlantic, it was shown that 5 loops are sufficient for more than half of the models to reach equilibrium with respect to the key diagnostic, the Atlantic Meridional Overturning Circulation (AMOC) maximum (Danabasoglu et al., 2014). In Appendix B the spin-up of the ocean in terms of two important diagnostics (Arctic liquid FWC and FW flux to the North Atlantic) is evaluated. It is shown that most of the models reach a good equilibrium state at the end of the experiment for the Arctic Ocean. 
Because the Arctic sea ice retreats in the recent decades and each model loop starts from the end of the preceding loop, the simulated Arctic Ocean experiences vigorous adjustment at the beginning of each loop. For example, the low sea ice extent and thickness at the end of 2007 increases after the atmospheric state is changed back to 1948 in the next model loop. When discussing the model results, we only take the last 30 model years of the 5th model loop, if not otherwise mentioned. Observations available for model evaluation are concentrated in the period of the last three model decades, which is another reason for us to focus on this period. Although our discussion focuses mainly on the last 30 years, in most of the plots of time series in this paper we show the whole 5th loop because the information can be useful for readers who are interested in a longer time period.

The paper is organized as follows. The mean state, interannual changes, and seasonal variability of liquid FW budget are discussed in Sections 2 , 3 and 4, respectively. The result of model ensemble mean is summarized in Section 5. The conclusion is given in Section 6. Some supporting information is shown in the appendices. The online supplementary material contains some additional results related to the topic.

\section{Mean state}

In this section we discuss the simulated mean state of Arctic liquid FW sources (Section 2.1) and mean state of Arctic FW storage (Section 2.2).

\subsection{Liquid freshwater sources}

\subsubsection{Transport through gateways}

The mean state of liquid FW budget terms are listed in Table 3. The Davis Strait liquid FW transport in the models correlates neither with the total number of cross-strait grid cells at the narrowest location of CAA, nor with horizontal resolution. For example, NCAR has coarser resolution and less cross-strait grid cells than the two MRI models, but it has larger liquid FW export at Davis Strait (Table 3). Liquid FW transport is determined by both ocean volume transport and salt transport (see Appendix A for definition). From Table 4 we can see that the Davis Strait ocean volume transport in NCAR is also larger than in the two MRI models. Therefore, we cannot simply link even 
Table 3: Mean and standard deviation of Arctic Ocean liquid freshwater (FW) source terms and freshwater content (FWC) relative to salinity 34.8. The last 30 years $(1978-2007)$ are used in the analysis. The standard deviation is calculated using annual mean time series. ${ }^{1}$

\begin{tabular}{|c|c|c|c|c|c|c|c|c|c|c|c|c|c|c|c|c|c|}
\hline & Observations & NCAR & AWI & MOM & MOM0.25 & CERFACS & CNRM & Kiel & $\mathrm{NOC}$ & $\mathrm{CMCC}$ & MRI-F & MRI-A & GOLD & FSU & Bergen & mean & spread \\
\hline \multicolumn{18}{|l|}{ Mean } \\
\hline Fram Strait & $-2660 \pm 528^{a}$ & -1461 & -2355 & -3932 & -2074 & -1320 & -1990 & -870 & -1141 & -1857 & -3481 & -1740 & -2496 & -3602 & -1023 & -2123 & 1017 \\
\hline Davis Strait & $-3200 \pm 320^{a, 2}$ & -2653 & -2410 & -1271 & -5955 & -4239 & -6248 & -2936 & -3744 & -3789 & -1513 & -1367 & -2658 & -786 & -2348 & -3119 & 1656 \\
\hline Bering Strait & $2500 \pm 300^{a, b}$ & 1650 & 2587 & 1717 & 2921 & 2732 & 3076 & 2840 & 2708 & 2908 & 2879 & 3175 & 662 & 2366 & 1928 & 2383 & 702 \\
\hline BKN & & 363 & 1246 & $\mathrm{~N} / \mathrm{A}$ & $\mathrm{N} / \mathrm{A}$ & 2180 & 3025 & -491 & 1684 & 1300 & 1774 & 1350 & $\mathrm{~N} / \mathrm{A}$ & 1053 & 1247 & 1174 & 733 \\
\hline $\mathrm{BSO}$ & $-90 \pm 94^{a}$ & -756 & -484 & -695 & -41 & -187 & -469 & -862 & -90 & -295 & -379 & -581 & -278 & -75 & -352 & -384 & 265 \\
\hline Surface flux & & 2570 & 147 & 1700 & 1844 & 1865 & 2010 & 406 & 457 & 1527 & -1133 & -129 & 1355 & 1697 & 1020 & 1190 & 991 \\
\hline Restoring flux & & 256 & 330 & -539 & 969 & 1613 & -465 & 124 & 1479 & 150 & 1182 & 3191 & $\mathrm{~N} / \mathrm{A}$ & -2438 & -627 & 170 & 1122 \\
\hline Arctic Storage & $8.53^{c}$ & 10.77 & 12.05 & 11.03 & 11.19 & 11.69 & 10.84 & 8.42 & N/A & 12.47 & 12.45 & 7.50 & 12.61 & 13.70 & 7.70 & 11.24 & 1.72 \\
\hline \multicolumn{18}{|c|}{ Standard deviation } \\
\hline Fram Strait & & 234 & 384 & 341 & 454 & 383 & 425 & 282 & 333 & 356 & 406 & 327 & 216 & 299 & 231 & 334 & 77 \\
\hline Davis Strait & $473^{d}$ & 254 & 527 & 158 & 817 & 822 & 867 & 532 & 683 & 799 & 466 & 502 & 383 & 119 & 376 & 523 & 260 \\
\hline Bering Strait & & 196 & 255 & 132 & 294 & 325 & 362 & 354 & 370 & 348 & 312 & 434 & 54 & 309 & 150 & 266 & 102 \\
\hline BKN & & 244 & 190 & N/A & N/A & 424 & 497 & 401 & 302 & 370 & 251 & 400 & $\mathrm{~N} / \mathrm{A}$ & 276 & 178 & 297 & 86 \\
\hline BSO & & 158 & 153 & 210 & 214 & 329 & 285 & 322 & 226 & 219 & 197 & 187 & 185 & 117 & 93 & 210 & 75 \\
\hline Surface flux & & 667 & 965 & 864 & 968 & 783 & 1016 & 940 & 791 & 541 & 934 & 1029 & 762 & 519 & 1005 & 827 & 169 \\
\hline Restoring flux & & 199 & 570 & 416 & 356 & 419 & 261 & 28 & 395 & 196 & 487 & 1164 & $\mathrm{~N} / \mathrm{A}$ & 645 & 421 & 366 & 172 \\
\hline Arctic Storage & & 0.19 & 0.13 & 0.21 & 0.29 & 0.17 & 0.33 & 0.30 & $\mathrm{~N} / \mathrm{A}$ & 0.19 & 0.21 & 0.36 & 0.11 & 0.14 & 0.08 & 0.20 & 0.08 \\
\hline
\end{tabular}

${ }^{1} \mathrm{FW}$ fluxes are shown in $\mathrm{km}^{3} /$ year, and FWC is in $10^{4} \mathrm{~km}^{3}$. Positive values indicate $\mathrm{FW}$ sources for the Arctic Ocean, and negative values indicate $\mathrm{FW}$ sinks. For the definition of $\mathrm{FW}$ transport and FWC see Appendix A. The FWC is integrated from ocean surface to the depth where salinity is equal to the reference salinity. Observational data reference: (a) Serreze et al. 2006, (b) Woodgate and Aagaard 2005, (c) Calculated from PHC3 climatology Steele et al., 2001, , (d) Curry et al. 2014).

${ }^{2}$ The estimate from Serreze et al. 2006) is based on the observation at Barrow Strait (in the eastern Parry Channel), not Davis Strait. Using a mooring array Cuny et al. 2005, estimated Davis Strait FW flux to be about $-2933 \pm 189 \mathrm{~km}^{3} /$ year for the period 1987-1990, not significantly different from the Serreze et al. 2006, approximation. The estimate by Cuny et al. 2005. was modified to $-4100 \pm 1900 \mathrm{~km}^{3} /$ year by Curry et al. 2014, using a new analysis method and updated knowledge on the transport on the shelves. Observations in the period 2004-2010 indicate that the Davis Strait FW flux decreased to $-2930 \pm 190 \mathrm{~km}^{3} /$ year Curry et al., 2014.

Table 4: The mean ocean volume transport $[\mathrm{Sv}]$ through the critical Arctic gateways and the standard deviation of the annual mean time series. The last 30 model years $(1978-2007)$ are used in the analysis. ${ }^{1}$

\begin{tabular}{|c|c|c|c|c|c|c|c|c|c|c|c|c|c|c|c|c|c|}
\hline & Observations & NCAR & AWI & MOM & MOM0.25 & CERFACS & CNRM & Kiel & $\mathrm{NOC}$ & $\mathrm{CMCC}$ & MRI-F & MRI-A & GOLD & FSU & Bergen & mean & spread \\
\hline \multicolumn{18}{|c|}{ Net volume flux } \\
\hline Fram Strait & $-2.0 \pm 2.7^{a}$ & -0.82 & -2.41 & -2.16 & -0.93 & -2.40 & -3.40 & -1.56 & -2.03 & -2.78 & -3.66 & -3.00 & -2.03 & -2.37 & -1.43 & -2.15 & 0.84 \\
\hline \multirow[t]{2}{*}{ Davis Strait } & $-2.6 \pm 1.0^{b}$ to & -1.57 & -1.11 & -0.53 & -3.38 & -2.53 & -2.85 & -2.55 & -2.21 & -2.23 & -0.79 & -0.97 & -1.27 & -0.52 & -1.80 & -1.80 & 0.92 \\
\hline & $-1.6 \pm 0.2^{c, 2}$ & & & & & & & & & & & & & & & & \\
\hline Bering Strait & $0.8 \pm 0.2^{d, e}$ & 0.78 & 1.08 & 0.66 & 1.15 & 1.21 & 1.26 & 1.35 & 1.22 & 1.21 & 1.31 & 1.32 & 0.25 & 1.16 & 0.82 & 1.04 & 0.32 \\
\hline BKN & & 1.69 & 2.42 & $\mathrm{~N} / \mathrm{A}$ & $\mathrm{N} / \mathrm{A}$ & 2.58 & 4.14 & 2.47 & 2.91 & 3.61 & 3.17 & 2.69 & $\mathrm{~N} / \mathrm{A}$ & 1.64 & 2.38 & 2.57 & 0.93 \\
\hline BSO & 2.0 to $2.3^{f, g, h}$ & 1.60 & 2.36 & 1.89 & 3.05 & 3.35 & 4.60 & 2.33 & 2.82 & 3.80 & 3.09 & 2.60 & 2.75 & 1.67 & 2.28 & 2.72 & 0.87 \\
\hline \multicolumn{18}{|c|}{ Standard deviation } \\
\hline Fram Strait & 0.3 to $4.7^{i}$ & 0.54 & 0.38 & 0.48 & 0.57 & 0.60 & 0.58 & 0.58 & 0.51 & 0.68 & 0.70 & 0.65 & 0.43 & 0.52 & 0.50 & 0.54 & 0.09 \\
\hline Davis Strait & $0.3^{c}$ & 0.16 & 0.22 & 0.10 & 0.48 & 0.53 & 0.47 & 0.42 & 0.38 & 0.51 & 0.29 & 0.37 & 0.21 & 0.11 & 0.33 & 0.32 & 0.15 \\
\hline Bering Strait & 0.6 to $1^{e}$ & 0.07 & 0.08 & 0.05 & 0.10 & 0.12 & 0.16 & 0.14 & 0.13 & 0.13 & 0.13 & 0.14 & 0.02 & 0.13 & 0.05 & 0.10 & 0.04 \\
\hline BKN & & 0.50 & 0.33 & $\mathrm{~N} / \mathrm{A}$ & N/A & 0.67 & 0.73 & 0.45 & 0.55 & 0.65 & 0.62 & 0.41 & $\mathrm{~N} / \mathrm{A}$ & 0.56 & 0.42 & 0.52 & 0.13 \\
\hline BSO & 0.8 to $2.9^{g}$ & 0.48 & 0.33 & 0.45 & 0.43 & 0.48 & 0.46 & 0.41 & 0.54 & 0.49 & 0.63 & 0.42 & 0.37 & 0.44 & 0.42 & 0.46 & 0.07 \\
\hline
\end{tabular}

${ }^{1}$ Positive values mean sources for the Arctic Ocean. (a) Schauer et al. 2008, (b) Cuny et al. 2005), (c) Curry et al. 2014), (d) Roach et al. [1995], (e) Woodgate and Aagaard 2005], (f) Smedsrud et al. 2010], (g) Skagseth et al. 2008, (h) Smedsrud et al. 2013, (i) Beszczynska-Moeller et al. 2011].

${ }^{2}$ The mooring data described by Cuny et al. 2005], were reanalyzed and combined with new knowledge on the transport on the shelves by Curry et al. 2014], leading to a new estimate of $-3.2 \pm 1.2 \mathrm{~Sv}$ for the 1987-1990 ocean volume transport, higher than the old estimate $(-2.6 \pm 1 \mathrm{~Sv})$ in Cuny et al. 2005). Recent observations show that the ocean transport at Davis Strait has declined to $-1.6 \pm 0.2 \mathrm{~Sv}$ in the period 2004-2010 Curry et al., 2014. 
the ocean volume transport to the basic configuration information listed in Table 2. Note that the model with the highest resolution (MOM0.25) does produce the largest Davis Strait volume transport, much larger than the $1^{\circ}$ GFDL-MOM. However, it is not known how much of the increased transport is caused by finer grid spacing and how much is associated with the enlarged strait width.

In addition to the representation of the straits (width, depth and grid spacing), numerical schemes (e.g., momentum advection and boundary conditions) may also influence the throughflow strength at straits (Penduff et al., 2007). It is beyond the scope of this study to explore how different factors impacted the volume and liquid FW transport in the CORE-II models. Unstructured-mesh models show the potential to improve the representation of narrow straits and ocean transport with locally increased resolution, without modifying the strait geometry (Wekerle et al., 2013). We have one unstructured-mesh model (FESOM) in this intercomparison project, but it did not employ mesh refinement in these straits.

The liquid FW transports show pronounced model spread at all gateways (Table 3). The largest spread is at Davis Strait, probably due to the difficulty in resolving the narrow CAA straits and difference in models' individual treatment. Ten models obtained larger liquid FW transport at Davis Strait than at Fram Strait, consistent to the observations (note that the difference in liquid FW transport between the two straits is insignificant according to available observations). FSU-HYCOM, GFDL-MOM, MRI-A and MRI-F have lower FW export at Davis Strait than at Fram Strait, and they also simulated much lower Davis Strait FW export than the observed. The Davis Strait liquid FW export is significantly overestimated in a few models, including CNRM, MOM0.25 and CERFACS. These three models are among those with largest ocean volume transport (Table 4 ).

The spread and difference in the simulated Davis Strait liquid FW transport can be explained largely by that of volume transport (Figure 2). However, the spread in salt transport is not negligible. For example, MOM0.25 has largest ocean volume transport, while CNRM has largest liquid FW transport; Kiel-ORCA05 and CERFACS have similar ocean volume transport, but the latter has much greater liquid FW transport.

At Fram Strait GFDL-MOM, FSU-HYCOM and MRI-F overestimate the upper bound of observed liquid FW transport. They are among the four models with the 

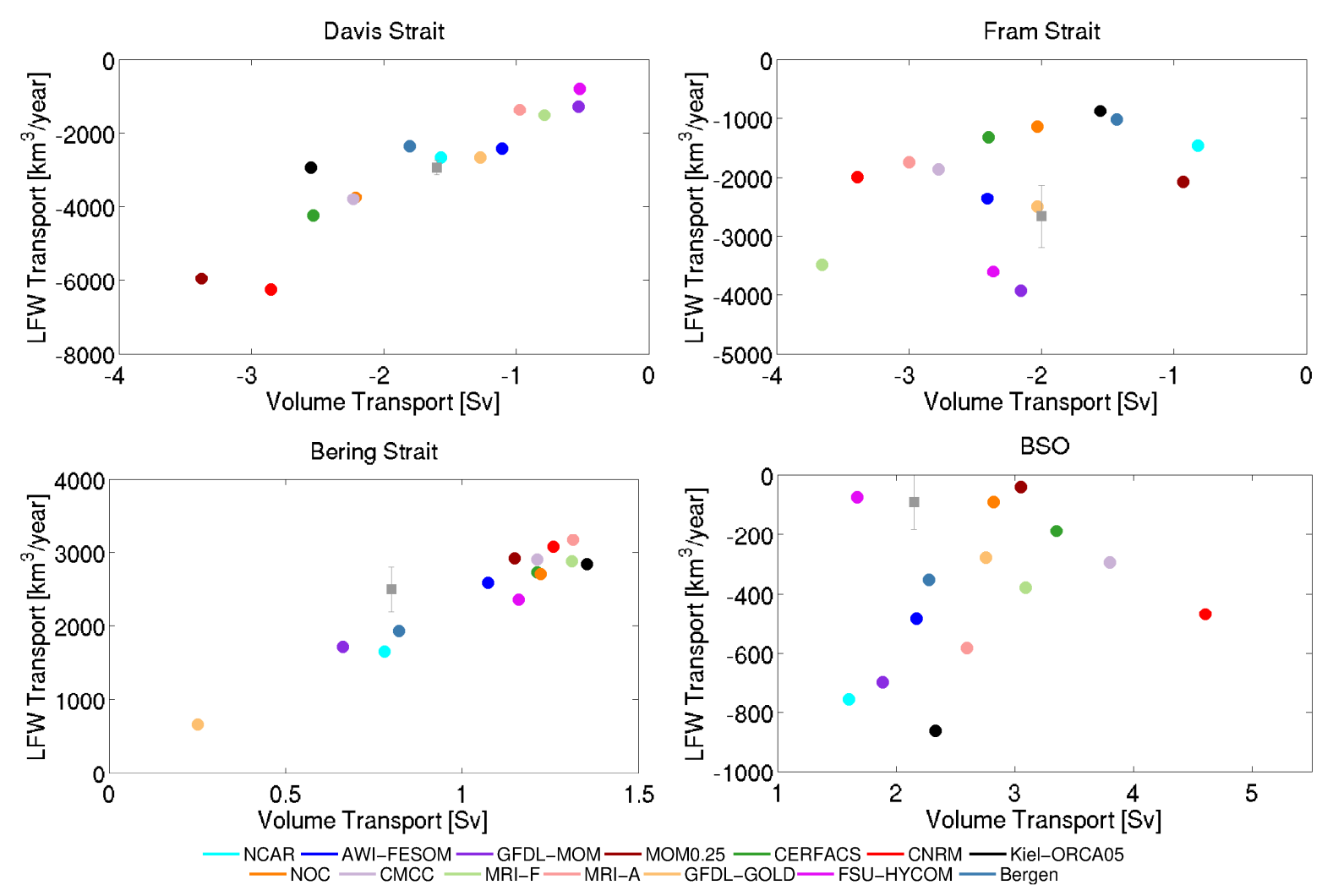

Figure 2: Liquid freshwater (LFW) transport versus volume transport. Observations are shown with gray squares, with error bars indicating the uncertainty for LFW transport. The values and reference for observations are shown in Tables 3 and 4 . Positive transport means source for the Arctic Ocean. 
lowest liquid FW transport at Davis Strait (the exception is MRI-A, which is an assimilated system). Most models tend to underestimate the Fram Strait liquid FW transport, with Kiel-ORCA05, Bergen, NOC and CERFACS having the lowest values (less than half of the observed value). No generally agreed correlation or anti-correlation for the mean liquid FW fluxes between Fram and Davis Straits is found among the fourteen models. This is also the case for volume transports. The mean liquid FW transport and ocean volume transport is not well correlated at Fram Strait (Figure 2), implying that the spread in both volume and salt transport contributes to that of liquid FW transport.

The Pacific feeds the Arctic Ocean with a liquid FW inflow of $2500 \pm 300 \mathrm{~km}^{3} /$ year through Bering Strait (Woodgate and Aagaard, 2005). The models produce a range of liquid FW transport from 662 to $3175 \mathrm{~km}^{3} /$ year (Table 3). Bering strait is relatively narrow and most models have two non-zero velocity grid cells (Table 2). The spread of the Bering Strait transport is not generally linked to the number of cross-strait grid cells among the models; however, for the two versions of MOM, the high resolution version MOM0.25 has larger transport than GFDL-MOM. Although MOM0.25 has eleven crossstrait grid cells, it has lower liquid FW and ocean volume transports at Bering Strait than MRI-A and CNRM, which have only two grid cells. Kinney et al. (2014) analyzed the ocean currents at Bering Strait in a few models and also found that models with finer horizontal grid spacing may get lower volume transport. The spread in the simulated liquid FW at Bering Stait is correlated with that in the volume transport, although the bias in salt transport certainly has some contribution to it (Figure 2).

Although the ocean volume transport at the BSO is towards the Barents Sea (Table 4), the liquid FW transport is negative (Table 3), which is because the mean salinity of inflow is higher than the reference salinity. Most of the models tend to overestimate both ocean volume inflow and liquid FW transport at the BSO. The low correlation between volume and liquid FW transports indicates that the spread of salt transport at the BSO has large contribution to the liquid FW transport spread.

Except for Kiel-ORCA05, the models agree that the Barents/Kara Seas supply liquid FW to the Arctic basin, that is, positive liquid FW transport at the BKN (Table 3), although the model spread is relatively large. It is consistent in the models that the Barents/Kara Seas lose liquid FW through lateral transports. Because the net solid FW 
flux entering the Barents/Kara Seas at the two gateways (and the associated melting FW flux at the ocean surface, see the solid FW budget in table 4 of Wang et al. (2015)) is lower than the total liquid FW flux leaving this region, the liquid FW supplied through P$\mathrm{E}+\mathrm{R}$ in the Barents/Kara Seas is an important component of the local freshwater budget. This is consistent with the observed scenario of FW budget described by Smedsrud et al. (2013).

\subsubsection{Surface freshwater budget}

Most of the models have positive liquid FW flux (into the ocean) at the ocean surface, except for MRI-F and MRI-A (Table 3). Although there are synthesized values for net precipitation (P-E) and river runoff for the overall Arctic FW budget (e.g., Serreze et al., 2006), we do not have a reference for liquid FW flux at the liquid ocean surface for the purpose of model evaluation. The simulated ocean surface FW fluxes have a large spread, with the largest values being about 17 times the lowest in the models with positive fluxes. Because the precipitation (rain and snow) and river runoff are prescribed fields in the CORE II forcing, the spread in the liquid FW surface flux is mainly due to the difference of sea ice thermodynamic growth rates and evaporation rates. Among the models for which the data of thermodynamic growth rates are available (see Table 4 of Wang et al. (2015)) and the surface liquid FW flux is positive, those with larger thermodynamic growth rates tend to have smaller surface liquid FW flux, implying the roles of sea ice formation in setting the strength of surface liquid FW flux. Although the solid and liquid FW budgets are linked through sea ice freezing/melting, no close connection is found between the solid and liquid FWCs among the models, indicating that the model spread in the mean state of the two forms of FWCs is unlikely of the same ice thermodynamic origin.

Global uncoupled ocean models typically use sea surface salinity (SSS) restoring to maintain stable meridional overturning circulation (see the discussion by Griffies et al., 2009). Different piston velocity for restoring is used in the CORE II models, with difference in the treatment of SSS restoring under sea ice (Danabasoglu et al., 2014). Surface restoring FW fluxes have the second largest spread in the liquid FW source terms (Table 3). Nine from the thirteen models with data available have positive fluxes, meaning that 
their simulated SSS in the Arctic Ocean is higher than the observed during the analyzed period.

\subsection{Liquid freshwater content}

The 2D distribution of liquid FWC (in meter, see Appendix A for its definition) averaged from 1993 to 2002 is shown in Figure 3. We choose this period motivated by the availability of objectively analyzed salinity observations (Rabe et al., 2014). The FWC in Figure 3 is the freshwater integrated from ocean surface to the depth where ocean salinity is equal to the reference salinity. Here we discuss the mean state, and the changes in the FWC spatial distribution will be analyzed in Section 3 .

The observation shows very low FWC in the Eurasian Basin and highest FWC in the Beaufort Gyre (BG). The major cause of large liquid FWC in the BG is suggested to be Ekman convergence associated with the Arctic High anticyclonic circulation centered in the BG region (Proshutinsky et al., 2002, 2009). MRI-A resembles the observation in both magnitude and distribution pattern owing to direct correction of temperature and salinity through data assimilation. It slightly underestimates the FWC in the Eurasian Basin, which might be the reason for its lower liquid FWC integrated over the Arctic Ocean (Table 3). The FWC in Kiel-ORCA05 has a magnitude and spatial distribution similar to the observation.

Most of the models tend to overestimate the liquid FWC in both the Eurasian and Canada Basins. Highest liquid FWC in the Eurasian Basin is seen in FSU-HYCOM and GFDL-GOLD. FSU-HYCOM has even higher FWC along the Lomonosov Ridge on the Eurasian side than on the other side, opposite to the observed distribution pattern. The pattern of high FWC located in the BG region (high contrast relative to the surrounding regions) is to some extent better represented by CMCC and MRI-F besides MRI-A, but these models have too high FWC magnitude.

The total liquid FWC integrated over the Arctic Ocean is higher than the observation in most of the models (Table 3). The source of overestimated liquid FWC is the applied SSS restoring fluxes (see Figure 17 and related discussions in Appendix B for details). 

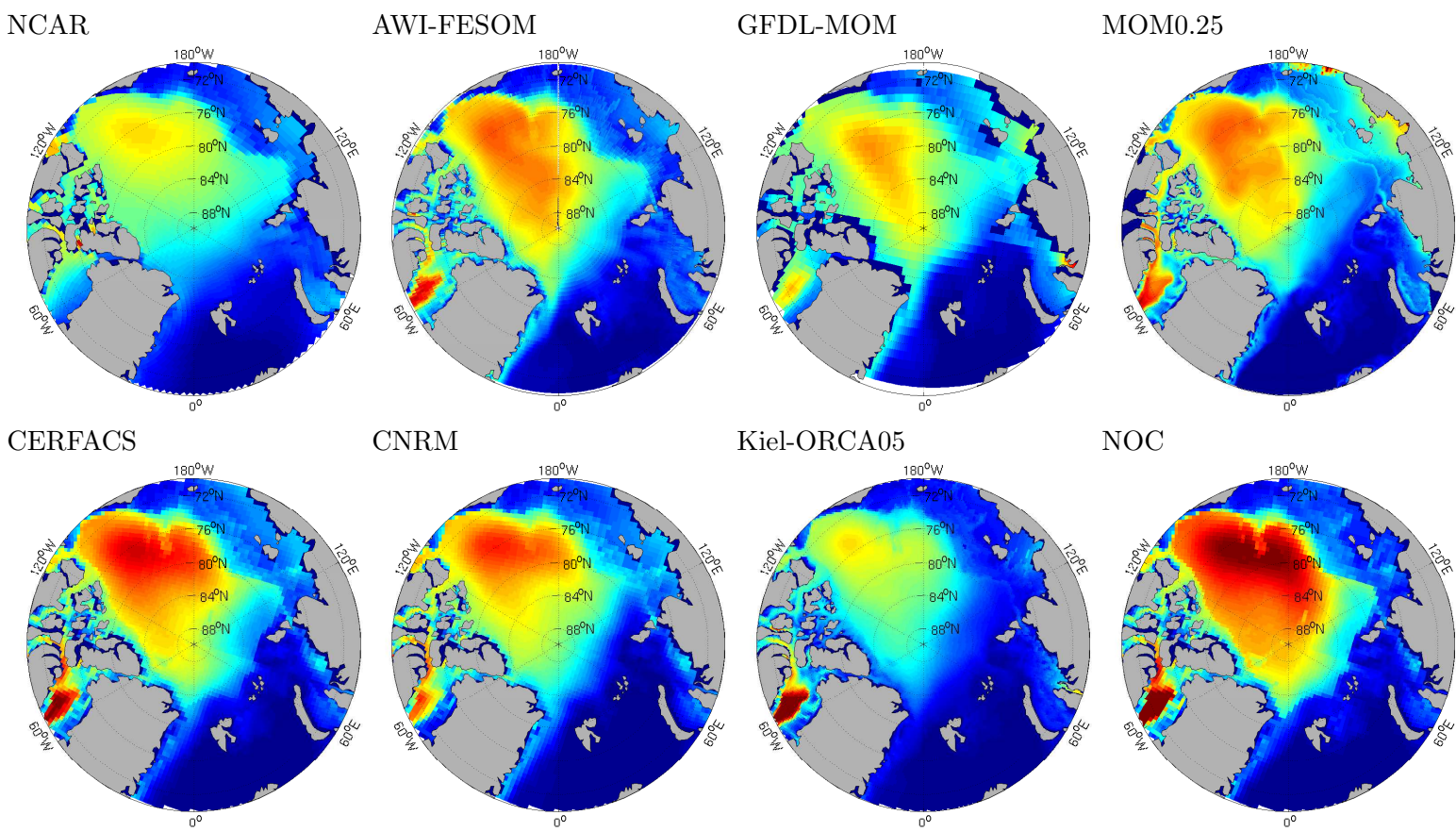

Kiel-ORCA05

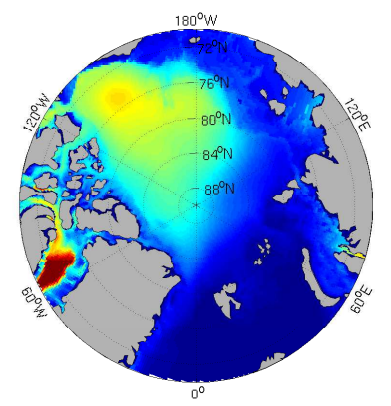

NOC

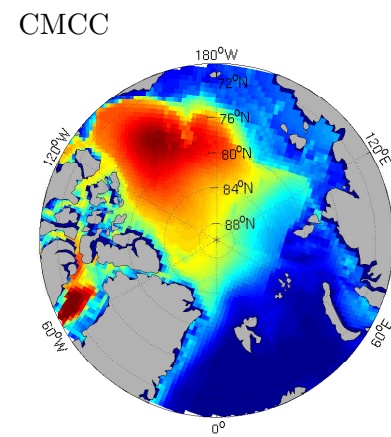

MRI-F

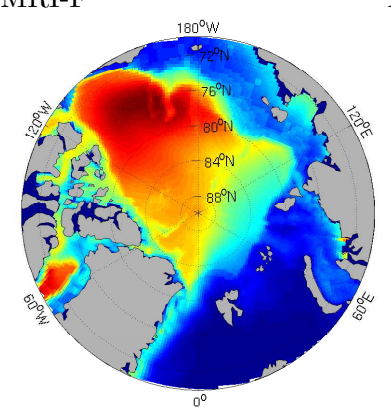

MRI-A
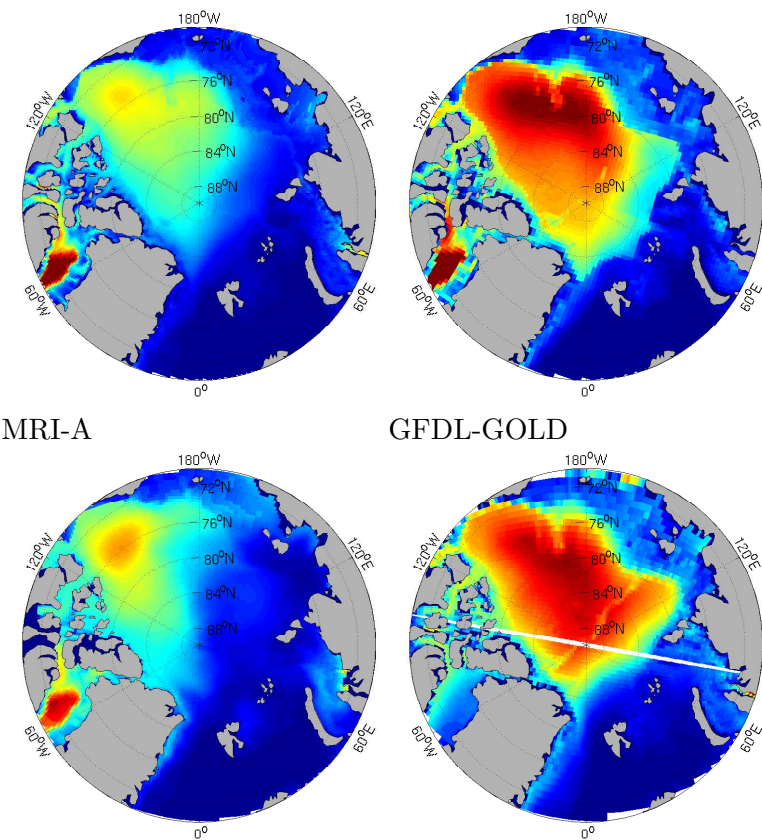

GFDL-GOLD

FSU-HYCOM

Bergen
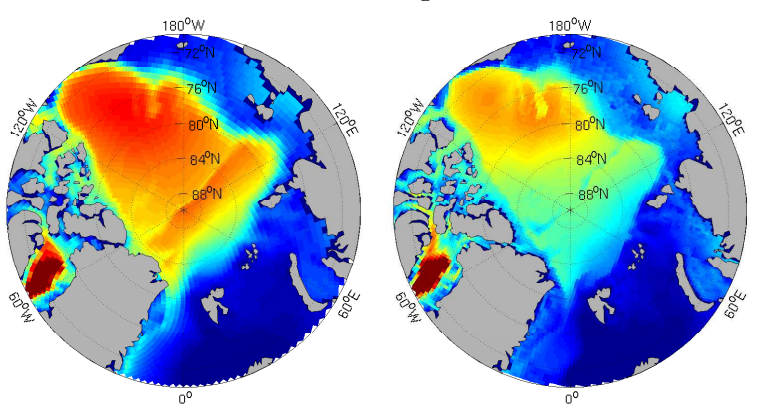

observation
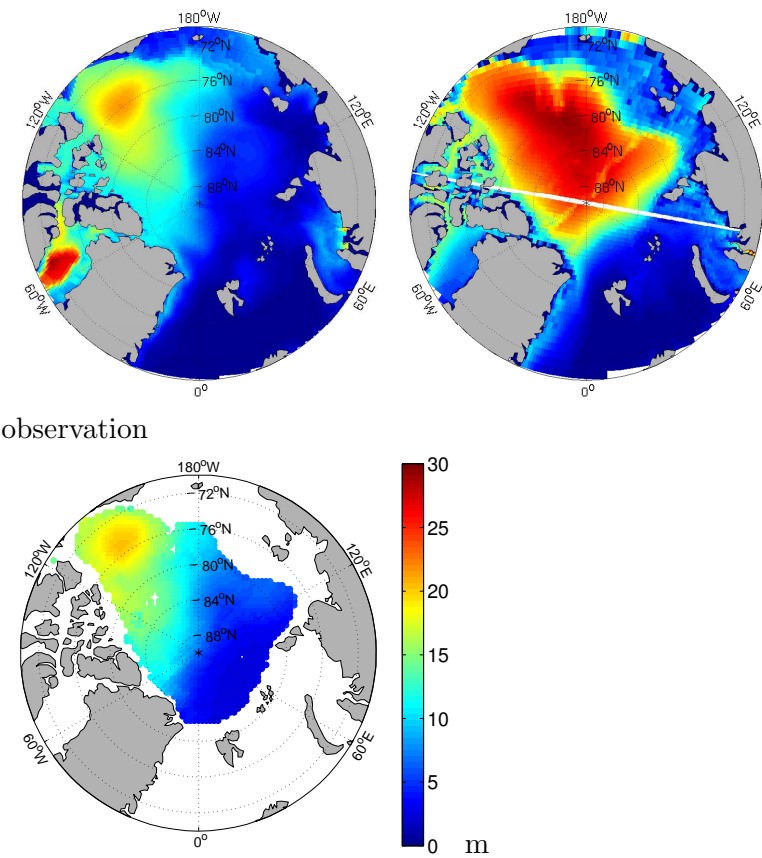

Figure 3: Liquid freshwater content [m] averaged from 1993 to 2002. The reference salinity is 34.8 and the integration in the vertical is taken from surface to the depth where salinity is equal to the reference salinity. The observation is based on the dataset of Rabe et al. (2014). 
In this section we will first discuss the statistics of the annual mean liquid FW budget. Then the interannual variability of liquid FW source terms, including transport through the Arctic gateways and ocean surface FW sources will be compared in Section 3.1. The variability of liquid FWC in the Arctic Ocean will be presented in Section 3.2, where both the FWC integrated over the Arctic domain and the FWC spatial distribution will be discussed.

The strength of interannual variability (defined by the standard deviation of annual means) of liquid FW transport at Davis Strait is comparable to or larger than that at Fram Strait, except for FSU-HYCOM and GFDL-MOM, which have the lowest liquid FW transport at Davis Strait (Table 3). At Davis Strait the models with the largest liquid FW transport, including CNRM, MOM0.25 and CERFACS, have the strongest variability. They also obtain relatively strong variability in their liquid FW transport at the Fram Strait. When we consider the suite of fourteen models, there is no close connection between the strength of liquid FW transports and the strength of their variability at Fram Strait, the BKN and BSO, while they are roughly correlated at Davis and Bering Straits. Surface FW fluxes have the strongest variability among the liquid FW source terms in most models, except for CMCC and CERFACS which have the strongest variability in their Davis Strait FW transport.

\subsection{Liquid freshwater sources}

\subsubsection{Transport through gateways}

The knowledge on Fram Strait liquid FW transport has been improved through ship campaigns carried out in summertime for a few years (1998, 2005, and 2008-2011, Rabe et al., 2009, 2013). However, the interannual variability before 2007 simulated in the CORE-II models cannot be assessed by using only two of these summer campaigns. The year-round moorings at Fram Strait starting from 1998 provided annual mean time series of liquid FW transport (de Steur et al. 2009, 2014), but the mooring arrays only covered the East Greenland Current (EGC) component in the Greenland continental slope region. The liquid FW transport does not show a pronounced trend in the observed decade, although a small increase is seen during the last few years (de Steur et al., 2009). Most 

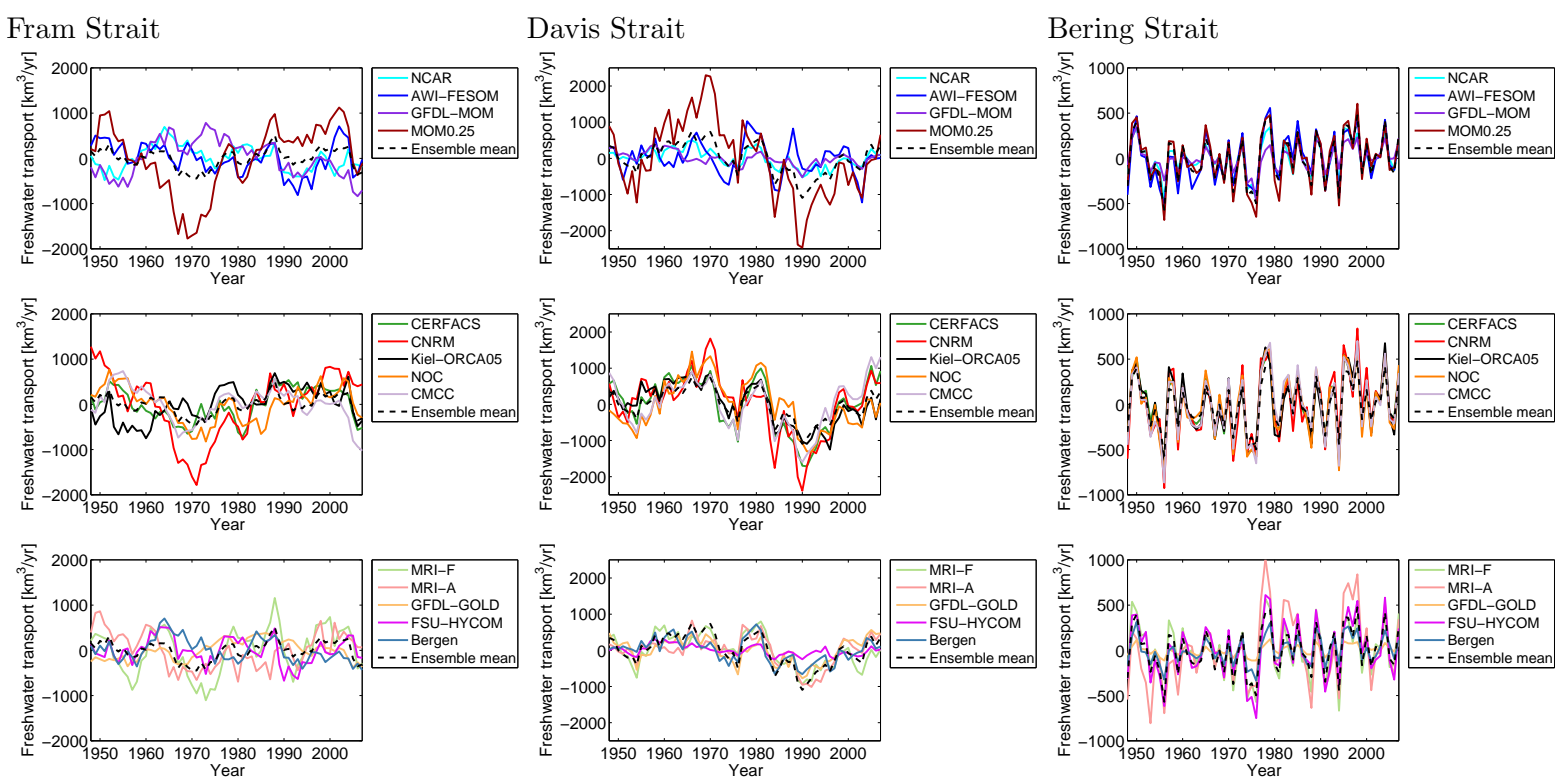

BK Northern Boundary

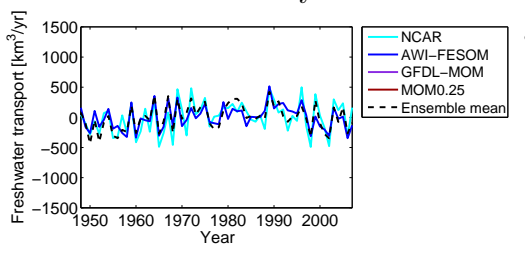

Barents Sea Opening
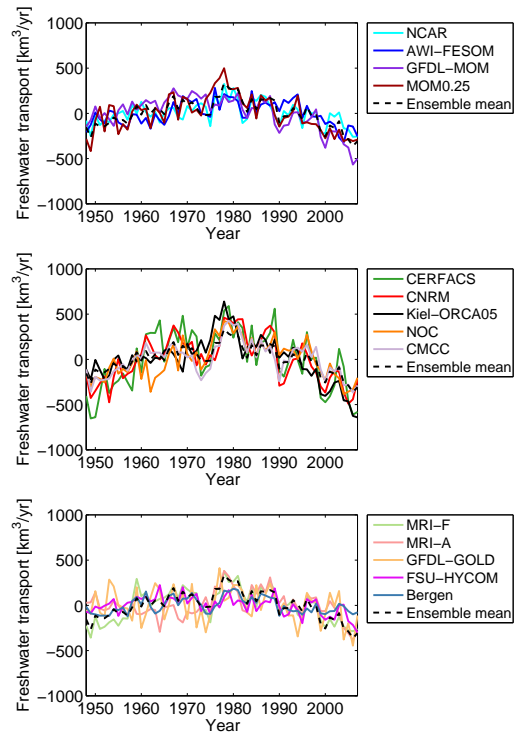

Figure 4: Anomaly of the annual mean Arctic liquid freshwater transport $\left[\mathrm{km}^{3} /\right.$ year $]$ through the Arctic gateways in the last model loop. Positive transport means source for the Arctic Ocean. 
of the models simulated an increase in the total Fram Strait liquid FW export in the last few years (Figure 4). This seems to be consistent to the observed change of the EGC component. The EGC component of the Fram Strait liquid FW flux was analyzed for the AOMIP models by Jahn et al. (2012). They found that some models do not have EGC in the longitude range of the mooring array, probably due to coarse model resolution. This indicates the difficulty of comparing available mooring data with models if we want to explore subsections.

The timing of liquid FW transport at Fram Strait is not well agreed in the models (Figure 4). Some features are similar in some of the models, for example, the increasing trend in the last few years, the high export phase at the end of 1960s, the low export phases at the end of 1980s and beginning of 2000s. However, the correlation between models is generally weak, with correlation coefficients rarely larger than 0.5 (the correlation coefficients of $\mathrm{FW}$ budget terms between models are shown in the online supplementary material). A few models show a descending trend in liquid FW export from the beginning of the 1970s to the end of the 1980s, particularly pronounced in MOM0.25 and CNRM, but the trend is much weaker or absent in the other models.

Although the variability of liquid FW transports does not agree among the models, the simulated volume transports at Fram Strait agree well (not shown). This has two implications: (1) Salt transports have large contribution to the variability of liquid FW transport at Fram Strait. It was found in previous studies that variations of velocity and salinity contribute to the interannual variability of Fram Strait liquid FW transport to the same extent (Lique et al., 2009, Jahn et al., 2010). (2) Salt transports do not have good agreement among the models. It was reported that the salinity driven variability is simulated less consistently than the velocity driven variability in the AOMIP models (Jahn et al., 2012). As a consequence, the correlation between liquid FW transport and ocean volume transport at Fram Strait is low (compared to the situation at Davis and Bering Straits, see Figure 5D. The results suggest that ocean models typically have difficulty in reproducing adequate salinity variation in the water masses exported towards the Fram Strait. In a model study Lique et al. (2009) found that the salinity variation is strongly influenced by sea ice melting/freezing north of Greenland, implying that sea ice models and ocean-ice interaction need to be improved in order to increase the fidelity of 
liquid FW transport at Fram Strait.
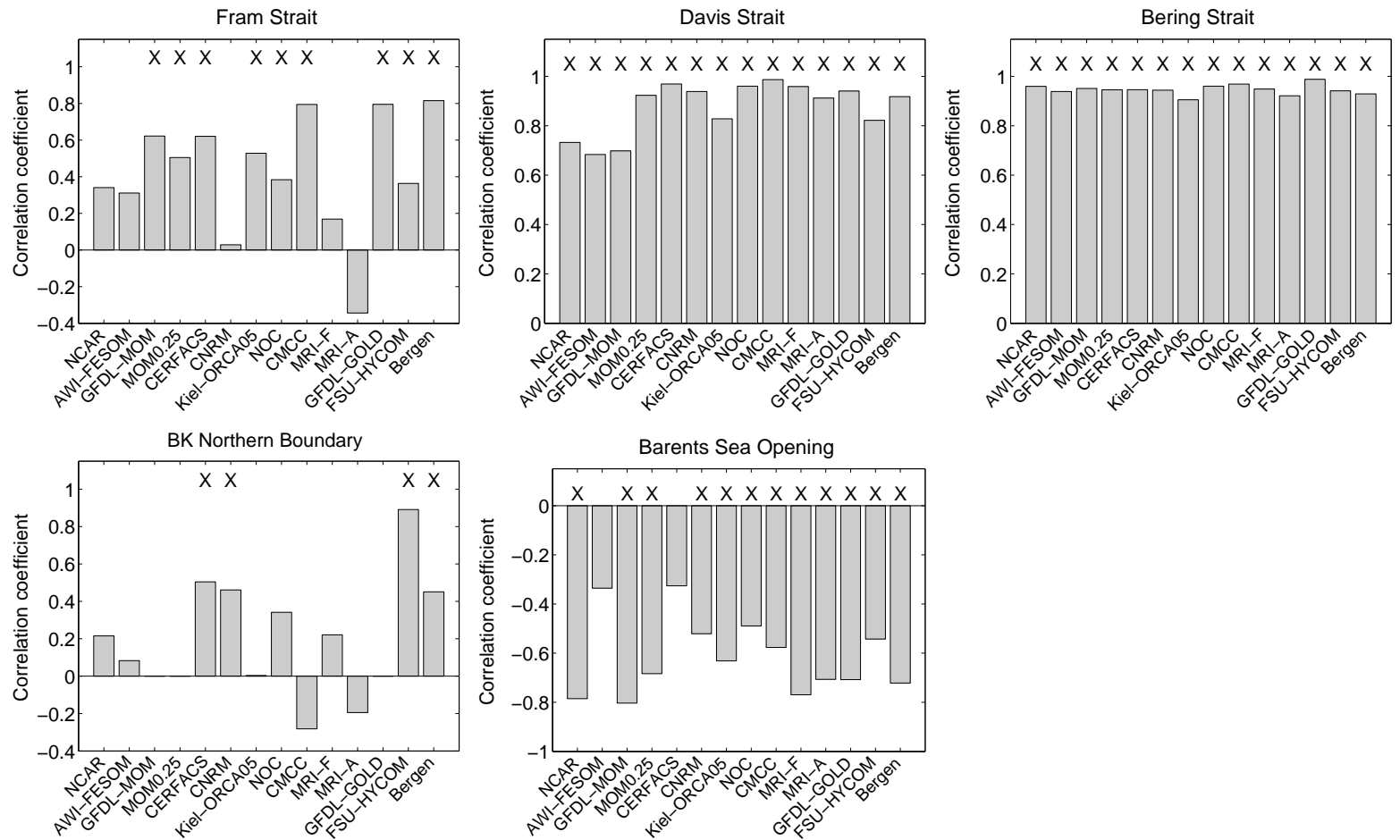

Figure 5: Correlation between annual mean liquid freshwater transport and ocean volume transport. Correlations significant at the $95 \%$ level are indicated with crosses ' $\mathrm{X}$ ' at the top of each panel.

The models show more consistent variability of liquid FW transport at Davis Strait than at Fram Strait (Figure 4). Decadal changes of Davis Strait liquid FW export also agree with each other: increasing from about 1980 to 1990, and then descending afterwards. The two models with largest liquid FW export at Davis Strait (CNRM and MOM0.25) show strongest decadal variations at both the Davis and Fram Straits. The volume and liquid FW transports are well correlated at Davis Strait in the models (Figure 5). This is consistent with the previous finding that the interannual variability of liquid FW transport at Davis Strait is mainly determined by that of volume transport (Lique et al., 2009; Jahn et al., 2010, 2012 , $^{3}$. The variability of ocean volume transport through

\footnotetext{
${ }^{3}$ Further analysis was taken to decompose the variability of $\mathrm{FW}$ transport into the velocity driven part and salinity driven part as done in Jahn et al. (2012). The velocity driven part has a larger magnitude than the salinity driven part at Bering and Davis Straits, and the velocity driven part is more consistently simulated by the models. This explains why the liquid FW transports are better agreed among the models at these two gateways than at Fram Strait and the BKN.
} 
Davis Strait is associated with the variability of SSH gradient across the CAA, which can be partly explained by the variation in the large scale atmospheric circulation (detailed analysis is given in the online supplementary material).
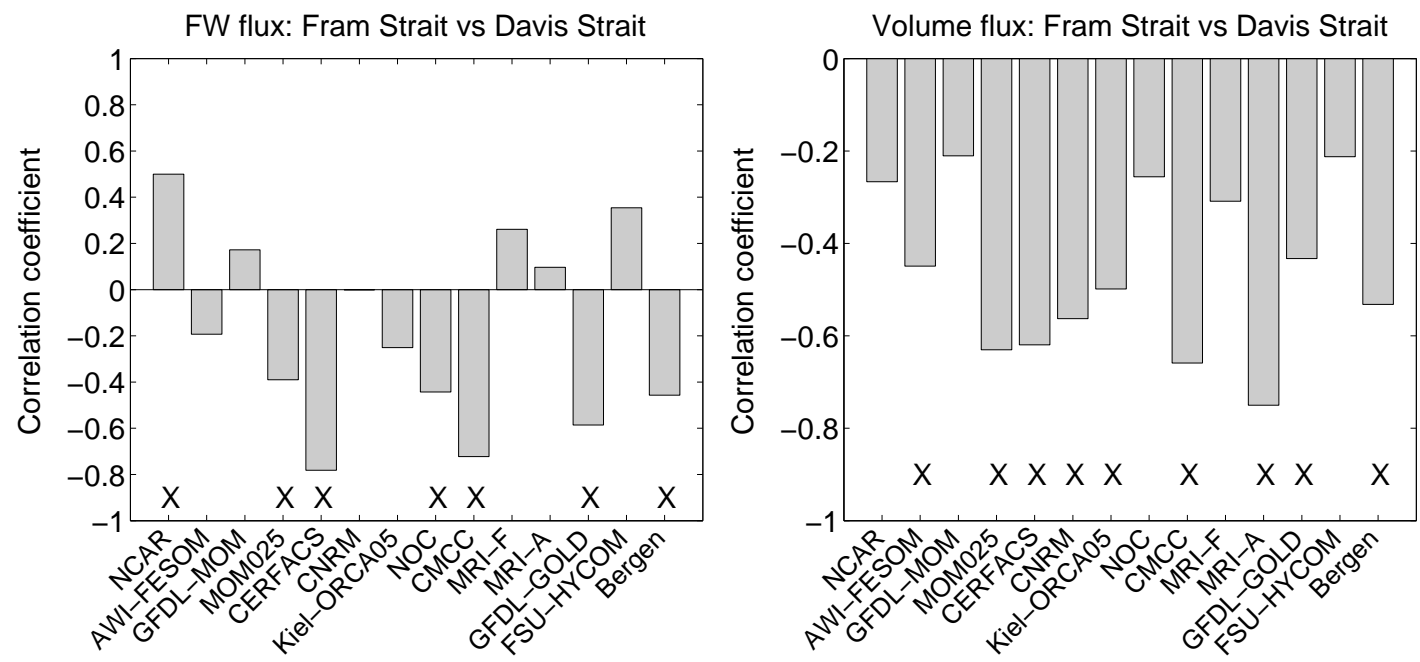

Figure 6: (left) Correlation of annual mean freshwater transports between Davis Strait and Fram Strait. (right) The same as (left) but for volume transport. Correlations significant at the $95 \%$ confidence level are indicated with crosses 'X' at the bottom of each panel. The last 30 years $(1978-2007)$ are used in the analysis.

The Arctic Ocean feeds the North Atlantic with FW through both Davis and Fram Straits. FW released from the two pathways might have different impact on deep water formation, so changing the distribution of FW export between the two gateways could alter the strength of meridional overturning circulation (Komuro and Hasumi, 2005). In Section 2.1 we mentioned that no generally agreed correlation or anti-correlation for mean liquid FW export between Fram and Davis Straits is found in the suite of fourteen models. Here it is interesting to see whether the liquid FW exports at the two gateways are connected inside each model.

Seven models have statistically significant (anti-) correlation between liquid FW transports at the two gateways, with six of them showing negative correlation (-0.4 to -0.8 at the $95 \%$ confidence level) and one showing positive correlation (Figure 6). Ocean volume transports at the two gateways are more consistently anti-correlated than liquid FW transports, but the degree of anti-correlation is model-dependent. It is significant at the 95\% confidence level in nine models. Lique et al. (2009) studied the Arctic freshwater budget using a particular version of NEMO model (ORCA0.25) and found very weak con- 
nection for liquid FW transport and strong anti-correlation for volume transport between the two gateways. Their conclusion applies to some of the CORE-II models, but clearly not all of them. This is similar to the finding from the AOMIP model study (Jahn et al., 2012). We do not have enough observational estimates to judge which model better simulated the variability and relationship of transports at the two straits, but it is obvious that the difference between the models is significant, warranting dedicated research.

The variability of liquid FW transports is most similar at Bering Strait (Figure 4). Observations show an increase of liquid FW inflow from 2001 to 2004, a drop in 2005 and an increase again afterwards (Woodgate et al., 2012). This variation is well captured by the models. The liquid FW transport is significantly correlated with ocean volume transport in all models (Figure 5), so the variability of ocean volume transport can largely explain that of liquid FW transport, consistent with the finding from observations that salinity is relatively stable on interannual time scales and volume transport drives the variation of liquid FW transport (Woodgate et al., 2006, 2012).

Ocean volume transport and liquid FW transport are closely linked in most of the models at the BSO (Figure 5). The liquid FW transport has consistent variability at the BSO. It has a persistent downward trend in the last few decades in all the models (Figure 4). This trend is consistent with the upward trend of BSO heat flux (Wang et al. 2015), and both can be explained by the tendency of Atlantic Water inflow (warmer and saliner).

The liquid FW fluxes into the Arctic basin at the BKN do not show persistent trend as at the BSO, and there is no significant correlation between the FW fluxes at the two gateways in all the models (Figure 4). This conforms with the fact that the ocean salinity is significantly modified inside the Barents/Kara Seas by surface FW flux (Smedsrud et al. 2013). At the BKN the correlation between liquid FW transport and ocean volume transport is not significant in most of the models (Figure 5), so salt transport has a large contribution to the variation of liquid FW transport. Some of the models have little agreement on the variability of liquid FW transport (Figure 4), indicating that the model representation of salinity in this region needs to be improved, similar to the case at Fram Strait. 


\subsubsection{Surface freshwater budget}

The variability of surface FW flux has good agreement among the models (see the online supplementary material). The good agreement stems from the fact that the variation of surface FW flux is predominately determined by that of sea ice melting/freezing (Figure 7), consistent to the previous model study by Köberle and Gerdes (2007). The comparison indicates that sea ice thermodynamic processes in the models consistently follow the variation and trend in the atmospheric forcing, despite the fact that the mean ice thermodynamic growth rates are different in the models (Wang et al., 2015).

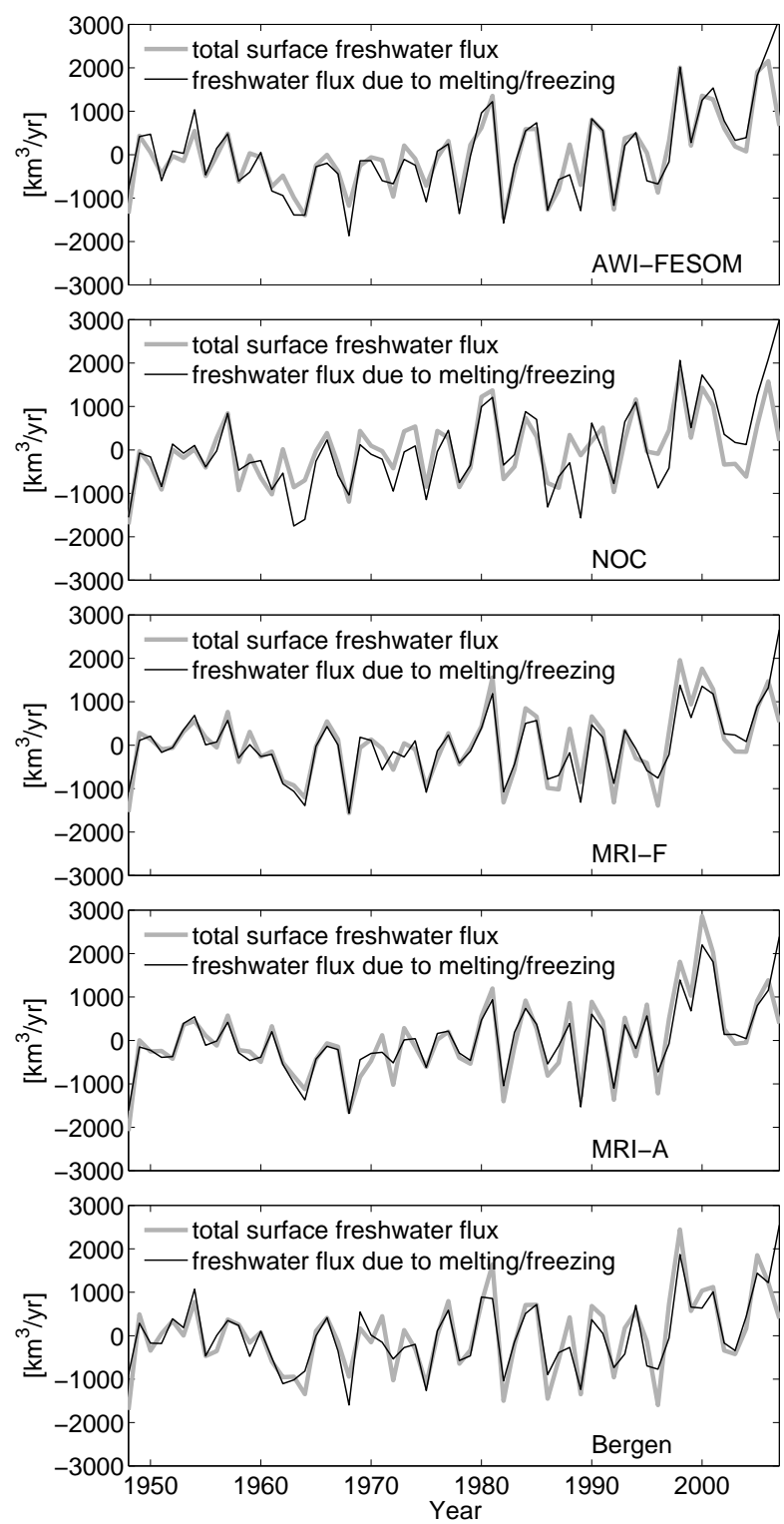

Figure 7: Anomaly of ocean surface freshwater (FW) flux and the FW flux due to sea ice melting and freezing. Five groups provided the data. Positive values mean source for the Arctic Ocean. 
The surface restoring FW fluxes have similar variability in most of the models (see the online supplementary material). As the SSS is restored toward the same climatological seasonal cycle in the models, the agreement for the variability of restoring flux implies similar variation of simulated SSS. The surface restoring flux is an artificial source for the Arctic FW budget. Its impact on Arctic FWC will be discussed in the next section.

\subsection{Liquid freshwater content}

We will first discuss the variability of total liquid FWC in the Arctic Ocean, and the relative contribution of the source terms to the changes of liquid FWC (lateral FW fluxes through Arctic gateways versus ocean surface fluxes). And then the changes in the FWC spatial distribution will be compared.

\subsubsection{FWC integrated over the Arctic Ocean}

The anomaly of liquid FWC for the last 60 years is shown in Figure 8. MRI-A has a time evolution of liquid FWC very different from other models. As the variability of MRI-F is very similar to the majority of the models, it is the assimilation scheme that introduced excessive variation in MRI-A. GFDL-MOM has a descending trend in its liquid FWC after 2000, different from all other models. Except for MRI-A and GFDLMOM, there is relatively good agreement on the time evaluation of liquid FWC among the models.

A rapid increase in the FWC in the Canada Basin has been found through salinity observations (Proshutinsky et al., 2009; McPhee et al., 2009). Rabe et al. (2014) objectively analyzed the observed salinity profiles for the period 1992 - 2012, and found a positive trend in liquid FWC in the upper Arctic Ocean starting from the mid of the 1990s. By analyzing the historical data available for more than a century, Polyakov et al. (2008, 2013 ) found that the 2000s are an exceptional decade with extraordinary upper Arctic Ocean freshening. The CORE-II models simulated the FWC upward trend after the mid of the 1990s (except in GFDL-MOM), although the magnitude of the increase is underestimated in some of the models. The recent increase of FWC (a fresher ocean) leads to an upward trend of halosteric sea level in the Arctic Ocean, especially in the Canada Basin, as shown by observations (Giles et al., 2012) and the analysis of the CORE-II models (Griffies et al., 2014) and other models (Koldunov et al., 2014). 

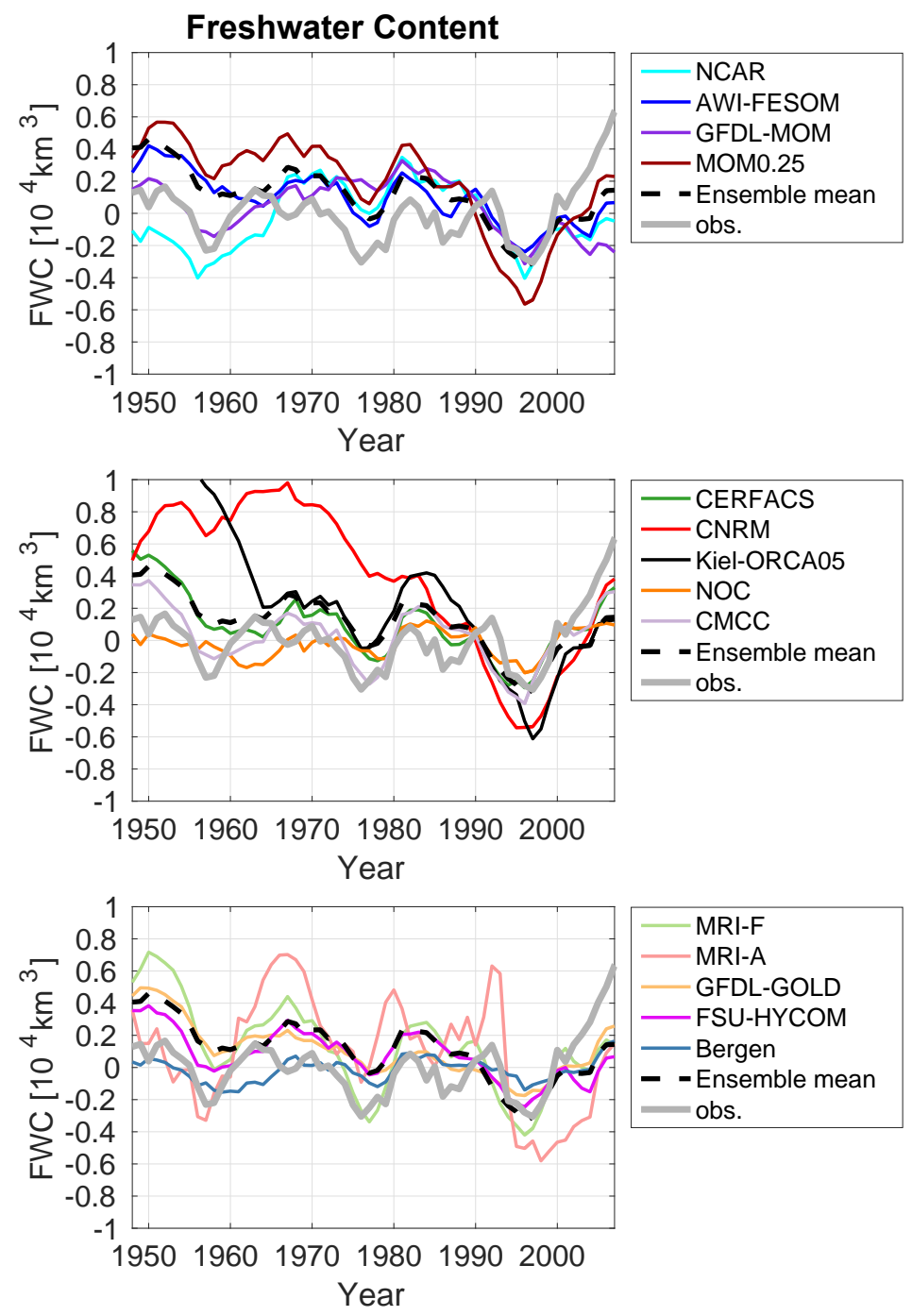

Figure 8: Anomaly of the annual mean Arctic liquid freshwater content $\left[10^{4} \mathrm{~km}^{3}\right]$ in the last model loop. The reference salinity is 34.8 and the integration in the vertical is taken from surface to the depth where salinity is equal to the reference salinity. The observation is based on the dataset of Polyakov et al. (2008, 2013). 

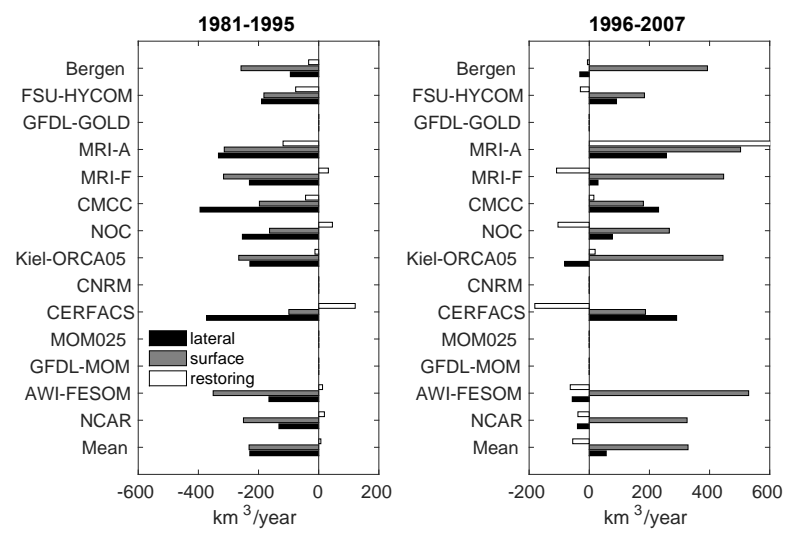

Figure 9: Mean liquid freshwater budget $\left[\mathrm{km}^{3} /\right.$ year] averaged over two periods: (left) 1981-1995 and (right) 1996-2007. The anomaly from the last 30 years mean $(1978-2007)$ is shown. Results for four models are not shown as some of their data are not available. Positive values mean source for the Arctic Ocean.

Figure 9 shows the mean values for different liquid FW sources averaged over the periods of 1981-1995 and 1996-2007 separately. The second period is characterized by an increasing trend (except in GFDL-MOM, see Figure 8). In the first period, both the surface FW flux and lateral FW transport have negative anomalies and contribute to the decrease of FWC, but there is no agreement on which source has a larger contribution. In the second period, surface FW flux changes to positive anomalies in all models, and most of the models also have positive anomaly with their lateral transport; the negative lateral transport anomalies (in NCAR, AWI-FESOM, Bergen and Kiel-ORCA05) are relatively small in magnitude. The positive anomaly of surface FW flux is larger than that of lateral transport in most of the models (except for CERFACS and CMCC) in the second period, indicating that the former contributes more to the increase of Arctic liquid FWC. The positive anomaly of surface FW flux is predominantly caused by reduced sea ice thermodynamic growth in recent years as shown in Figure 7 . The model results are consistent to the finding about the role of sea ice changes on the variation of liquid $\mathrm{FWC}$ by Polyakov et al. 2008, 2013).

On average the simulated increasing rate of liquid FWC after the mid-1990s is only about half of the observed (Figure 8). The models tend to underestimate the recent decline in sea ice thickness and volume (Wang et al., 2015), which may partly explain the underestimated trend of liquid FWC. The restoring FW flux is an artificial source for 
the liquid FWC. On the interannual time scale it tends to anti-correlate with the ocean surface FW flux (see Appendix C). The applied restoring fluxes have negative anomalies in the recent years in most of the models (Figure 9). They act to compensate the FWC increase induced by the other FW sources. The model uncertainty in FW fluxes through the Arctic gateways is significant (Figure 9), to which the uncertainty in the simulated FWC variation may also be partly attributed.

\subsubsection{FWC spatial distribution}

In the Arctic region atmospheric forcing can influence the spatial distribution of liquid FWC through different processes. Variation of Arctic anticyclonic atmospheric circulation can change the location and strength of the liquid FWC high in the Beaufort Gyre (BG) by modulating convergence/divergence of Ekman transport (Proshutinsky et al., 2002, 2009; Giles et al. 2012). Changes in atmospheric circulation associated with the positive phase of the Arctic Oscillation (AO) can modify the ocean pathway of Eurasian river runoff, directing it towards the Canada Basin, thus increasing the FWC there (Morison et al., 2012).

The difference in the FWC spatial distribution between 1993-2002 and 2003-2007 is shown in Figure 10 and we will examine how well the models can capture the observed changes. Note that the choice of the two averaging periods is arbitrary, based on the fact that we have 5-yr averaged model salinity data and statistically reliable observations analyzed for these years (Rabe et al., 2014). The observation shows an increase in liquid FWC on both sides of Lomonosov Ridge in the later period, and the strongest increase takes place along the outer rim of the Canada Basin. The models differ from the observation in both the location and strength of major changes. Different from the pattern shown by the observation, most models show an increase in liquid FWC centered at $80-84^{\circ} \mathrm{N}$, $160-180^{\circ} \mathrm{W}$, including NCAR, GFDL-MOM, CMCC, MRI-F, MRI-A, GFDL-GOLD, FSU-HYCOM and Bergen. Kiel-ORCA05 has pronounced increase in the Eurasian Basin and decrease along the southern boundary of the Canada Basin, while NOC has a strong decrease in the eastern Eurasian Basin. MOM0.25 better captured the observed spatial pattern of changes, although the magnitude of these changes is overestimated. We conclude that the variability of the total Arctic liquid FWC can be reproduced by most of 


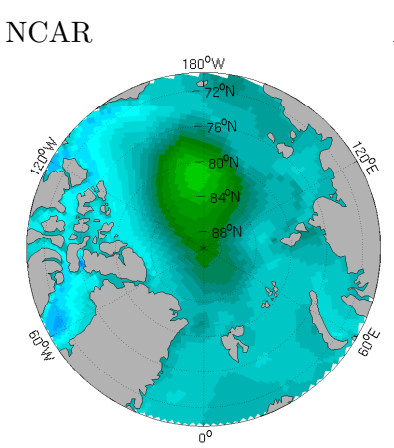

CERFACS

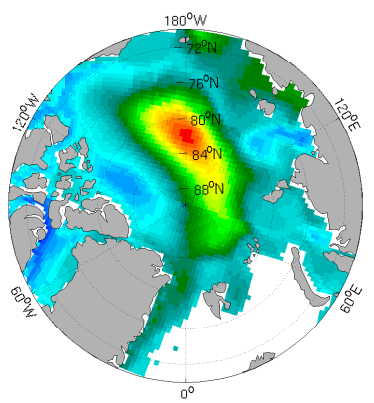

CMCC

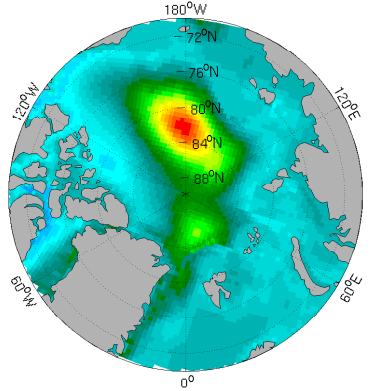

FSU-HYCOM

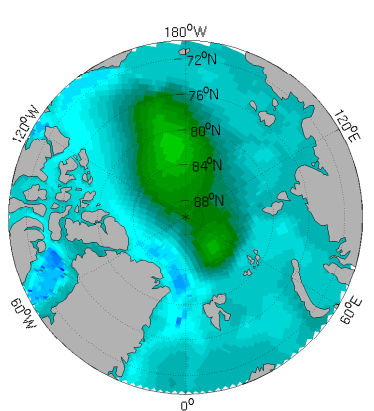

AWI-FESOM

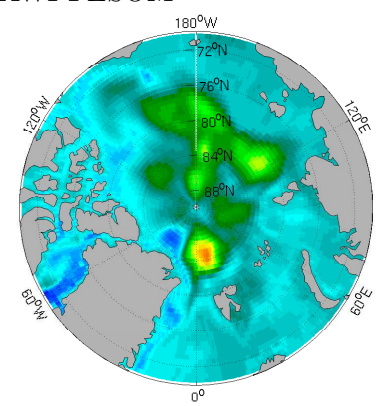

CNRM

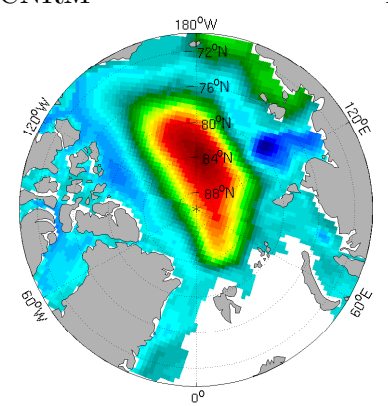

MRI-F

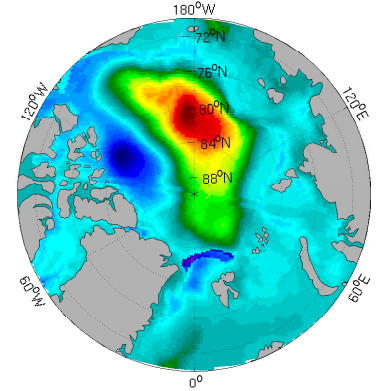

Bergen

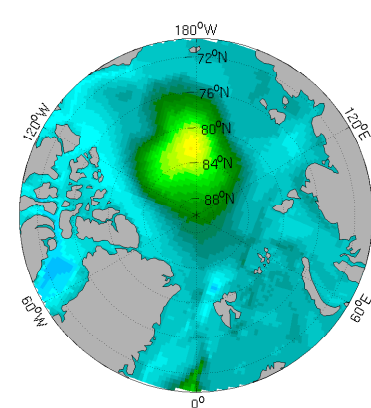

GFDL-MOM

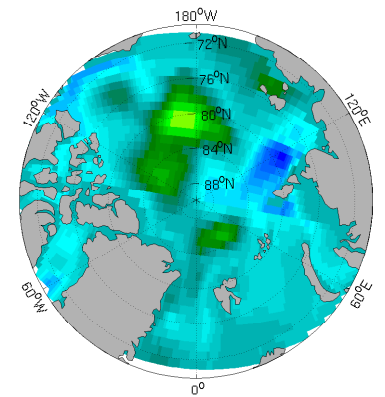

Kiel-ORCA05

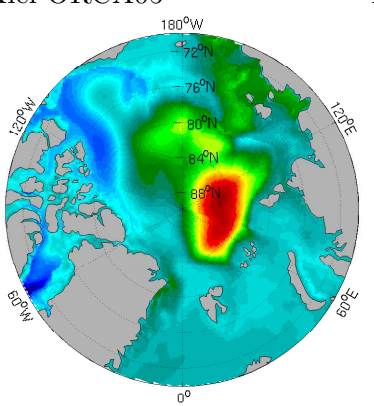

MRI-A

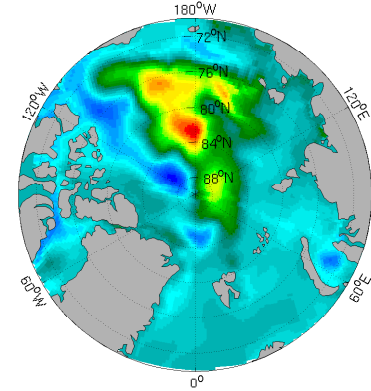

observation

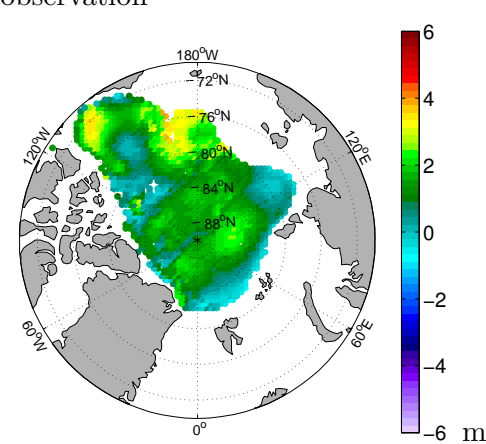

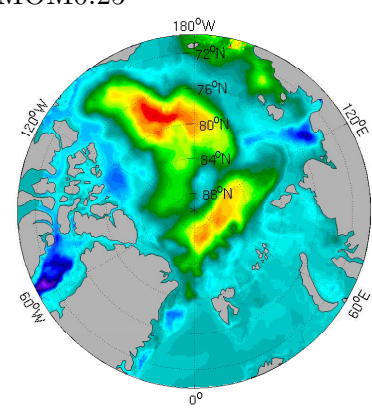

NOC

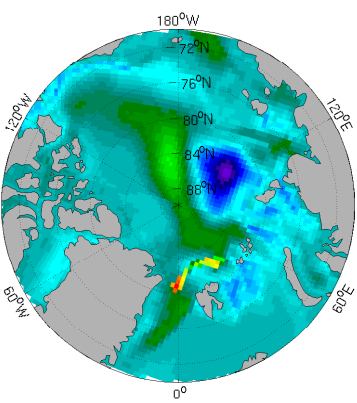

GFDL-GOLD

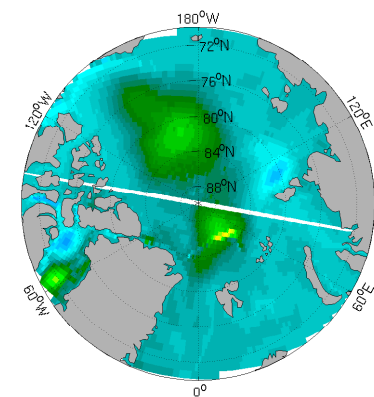

Figure 10: The difference of liquid freshwater content [m] between the period 2003-2007 and 1993-2002. The reference salinity is 34.8 and the integration in the vertical is taken from surface to the depth where salinity is equal to the reference salinity. The observation is based on the dataset of Rabe et al. (2014). 
the models, but the variation of spatial distribution is not well simulated. MOM0.25 simulates the spatial pattern somewhat better, so we speculate that model resolution might be helpful in representing the response of FWC spatial distribution to atmospheric forcing. This is also suggested by Koldunov et al. (2014) in their model intercomparison of the Arctic SSH, which has variation mainly caused by that of the halosteric component. They found that the spatial distribution of SSH is better represented in the highest resolution model among the three models that use the same model code but different resolutions.

\section{Seasonal variability}

The models show minimum liquid FW export in May to June and maximum between September and November at Fram Strait, while the ocean volume export has minimum between May and August and maximum between November and February (Figure 11). These results are very similar to those found in the suite of AOMIP models (Jahn et al., 2012). The seasonal cycle of liquid FW transport does not correlate with the ocean volume transport, meaning that the seasonal variation of salinity and salt transport is large and not in phase with volume transport. The relatively good agreement for both ocean volume transport and liquid FW transport among most of the models indicates that they also have agreement on the seasonality of salt transport. Although the timing of the liquid FW transport seasonal cycle is similar among the models, the magnitude of the seasonal cycle strongly varies, with the largest in MRI-F and smallest in KielORCA05. The very small magnitude in Kiel-ORCA05 is due to its too large magnitude of salt transport variability, because the magnitude of its volume transport seasonal cycle is not small compared to other models.

At Davis Strait the ocean volume export has maximum between July and August and minimum in October and November in most of the models (except for Bergen and Kiel-ORCA05 which have maximum in March), different from the phase of liquid FW export (Figure 11). The liquid FW transport and ocean volume transport in the CAA straits are well correlated with each other on both seasonal and interannual time scales as shown by observations (Prinsenberg and Hamilton, 2005, Peterson et al., 2012) and a high resolution model study (Wekerle et al., 2013). The water masses exported from the 
Freshwater transport
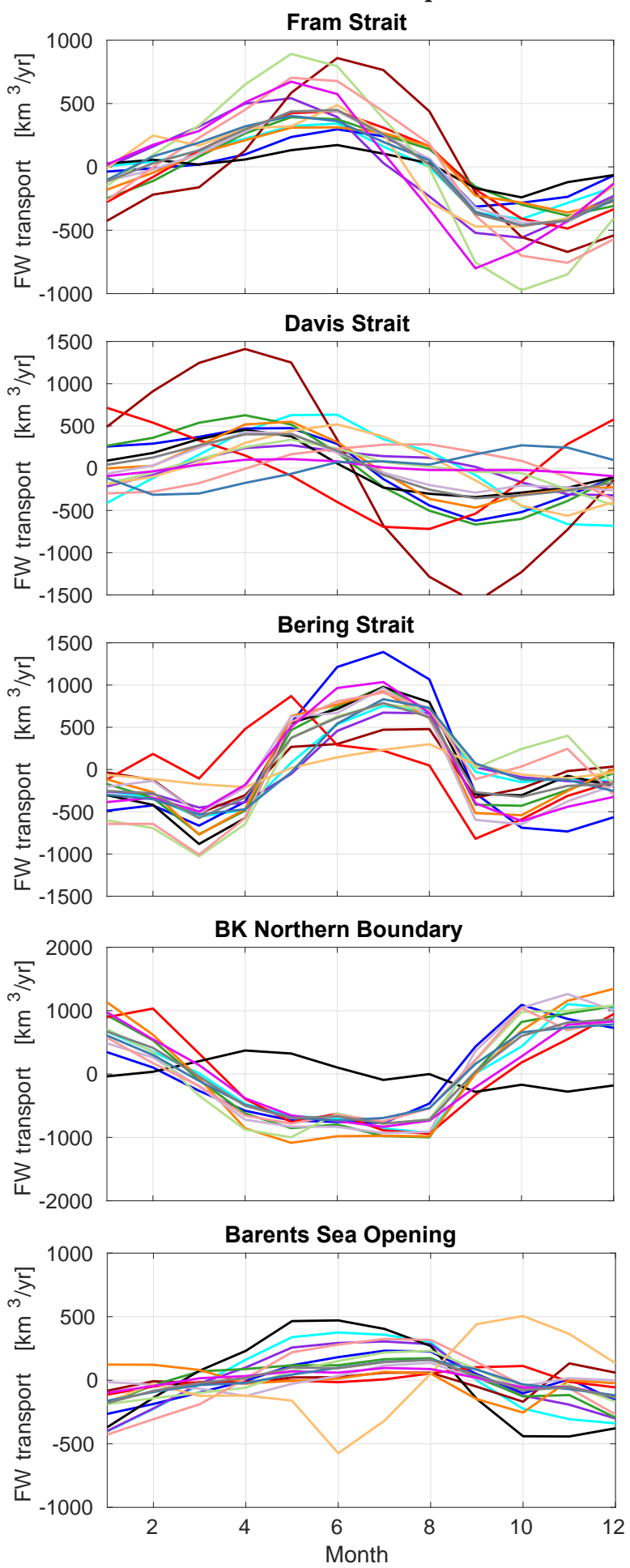

- NCAR - AWI-FESOM - GFDL-MOM-MOM0.25 - CERFACS - CNRM - Kiel-ORCA05
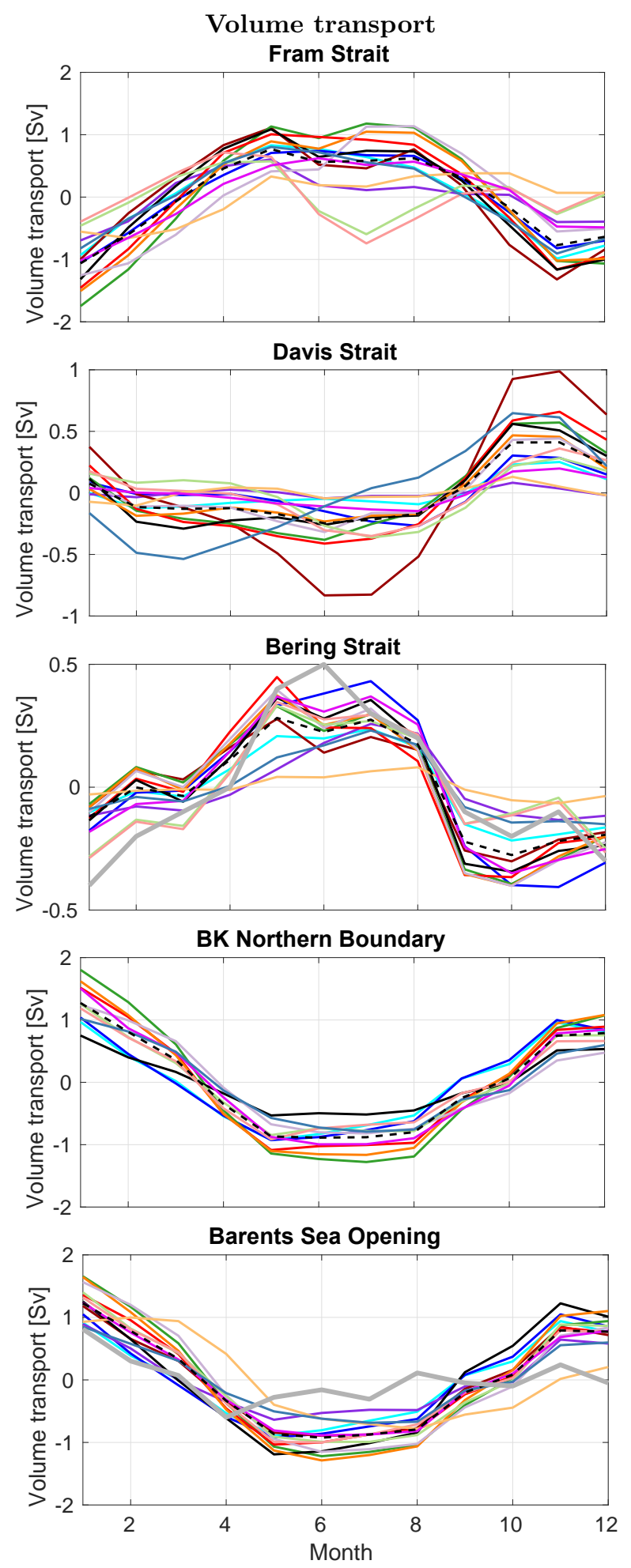

Figure 11: Seasonal variability of (left) liquid freshwater and (right) ocean volume transport. Ensemble means are shown with dashed lines and available observations are shown with thick gray lines. The observed volume transport seasonal variability at Bering Strait is described by Woodgate et al. (2005) and at BSO by Smedsrud et al. (2010). Positive transport means source for the Arctic Ocean. The average is over the last 30 model years (1978 - 2007). 

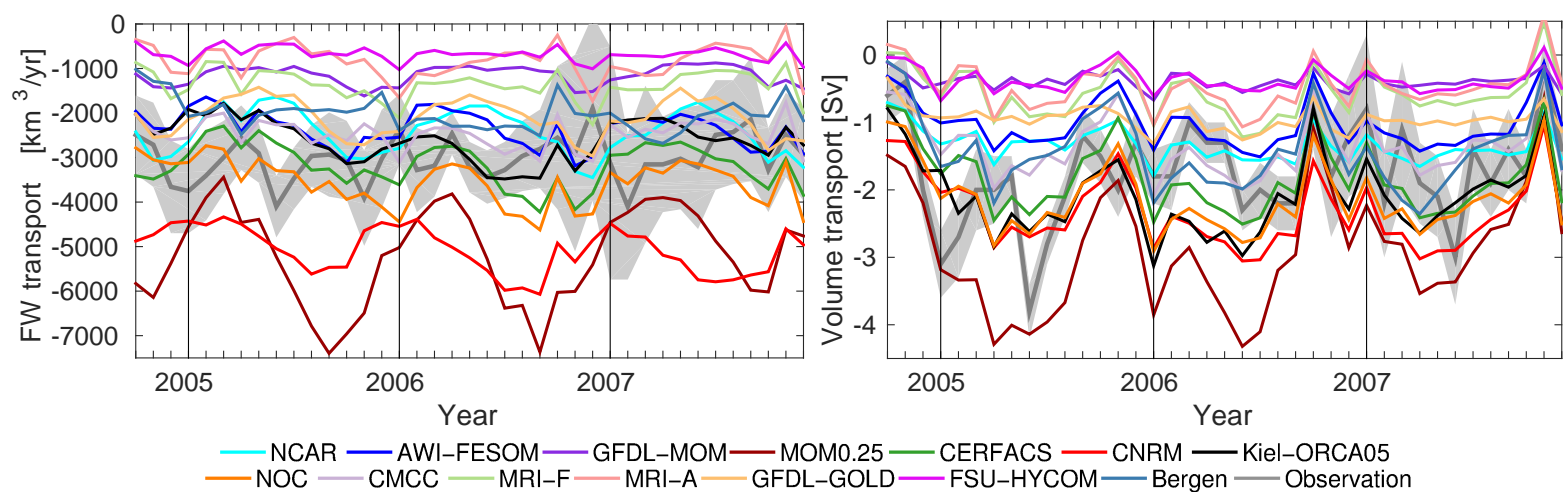

Figure 12: The monthly (left) liquid freshwater and (right) ocean volume transport at Davis Strait. Observations are shown with gray curves and the uncertainty is shown in the light gray background. The observations are described by Curry et al. (2014). Positive transport means source for the Arctic Ocean.

CAA flow southwards as the upper component of the Baffin Island Current. When they reach the Davis Strait, the liquid FW transport and ocean volume transport are still well correlated as shown in the observations by Curry et al. (2014) (the first column in their Figure 9). It implies that surface fluxes and other local processes along the pathway from the CAA to the Davis Strait do not destroy the correlation relationship between FW and ocean volume fluxes. However, when the liquid FW transport is calculated across the whole Davis Strait transect, including the northward West Greenland Current (WGC) and the southward flow of transitional water, the correlation with the ocean volume transport becomes lost (see the last column in Figure 9 of Curry et al. (2014)). Therefore it is the WGC that modifies the net liquid FW transport at Davis Strait, thus its seasonal phase relative to the ocean volume transport. This explains why the liquid FW transport and ocean volume transport are not correlated in most of the models (Figure 11). The good correlation on interannual time scales (Figure 5) implies that the WGC does not significantly modify the interannual variation of net liquid FW transport at Davis Strait. This is consistent to the observation that the WGC has lower interannual variability than other water masses in Davis Strait (Curry et al., 2014).

The monthly mean liquid FW transport and ocean volume transport at Davis Strait

\footnotetext{
${ }^{4}$ In the context of our discussion the WGC contains both fresher water of the East Greenland Current (EGC) origin and saltier water of the Irminger Current origin.
} 
for the period when the model simulations and observation coincide are shown in Figure 12. The models reproduced large variation events for the ocean volume transport better than for the liquid FW transport. The model spread is also more pronounced in the liquid FW transport. We speculate that the seasonal variation of salt transport in the WGC is not consistently simulated in the models, which needs to be investigated in future work.

At Bering Strait the observation shows maximum volume inflow in June and minimum in January (Woodgate et al., 2005). The models have similar seasonal variation, and the timing is largely consistent with the observation. The liquid FW transport is in phase with the volume transport, because the variation of salinity is small on the seasonal time scale as also shown by observations (Woodgate et al., 2005).

At the BKN the liquid FW transport (associated with low salinity inflow from the Barents/Kara Seas into the Arctic basin) is consistent in the models, and it is in phase with the ocean volume transport (except for Kiel-ORCA05). The correlation on the seasonal time scale is better than on the interannual time scale (Figure 5). The salinity in the Barents Sea is low in summer and high in winter (as also shown by observations at the Kola section), which is in phase with the volume transport. This can explain the good seasonal correlation between the ocean volume and liquid $\mathrm{FW}$ transport at the BKN. Kiel-ORCA05 has opposite phase in its seasonal cycle; note that its net FW transport at the BKN also has a sign opposite to other models (Table 3).

The models show similar seasonal cycle of ocean volume transport at the BSO. They have minimum volume inflow from May to August, later than the timing in observation. Arthun et al. (2012) interpolated their model data to the location of moorings to compute heat flux at the BSO, and found that better agreement between model results and observations can be obtained. They concluded that the available moorings under-sampled the current at the BSO. We speculate that the difference between the simulated and observed ocean volume transport can be partly due to the low spatial resolution of moorings. The liquid FW transport (net outflow of FW due to high salinity Atlantic Water inflow into the Barents Sea) is anti-correlated with the ocean volume transport in the models (except for GFDL-GOLD).

The models agree on the seasonality of surface FW flux, with maximum in July and minimum in November, December and January (Figure 13). The seasonal variation of 

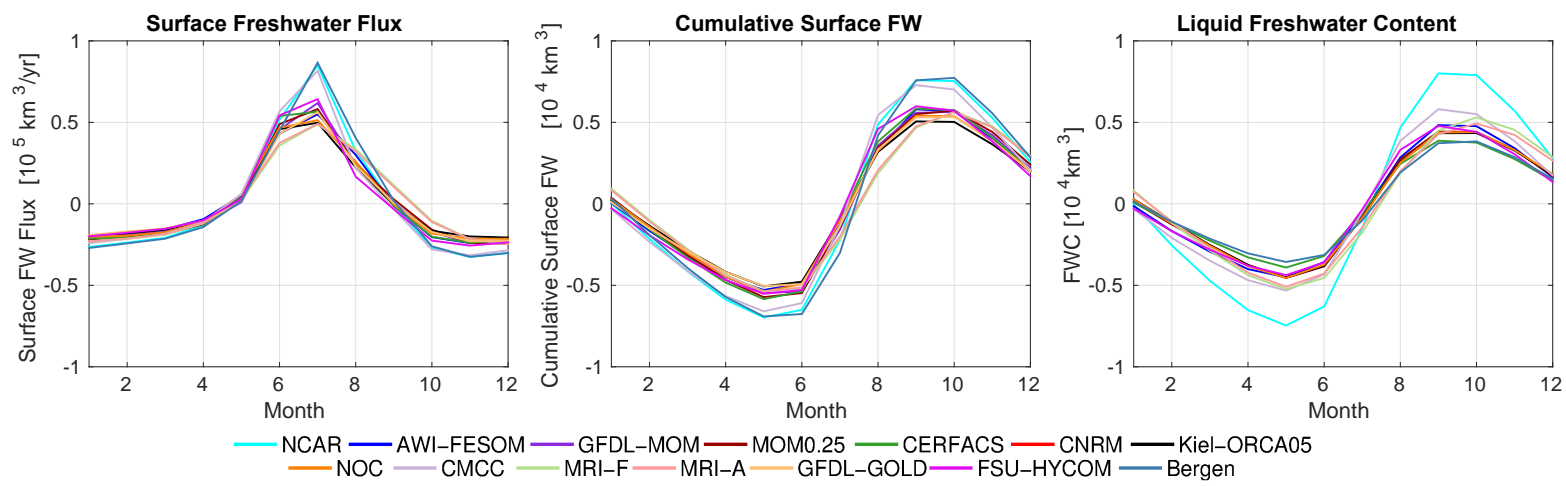

Figure 13: (left) The mean seasonal cycle of Arctic surface freshwater flux and (middle) the corresponding cumulative freshwater amount. (right) The mean seasonal cycle of Arctic liquid freshwater content. The average is over the last 30 years $(1978-2007)$.

ocean surface FW flux is mainly induced by sea ice melting/freezing (not shown). The seasonal variation in the Arctic liquid FWC is predominantly caused by the seasonal variability of surface FW flux, and the contribution from other source terms (transports through gateways and the SSS restoring flux) is much smaller.

\section{Summary on the model ensemble mean}

We summarize the simulated liquid FW budget based on the model ensemble mean in this section. Other conclusions will be given in the last section (Section 6).

\section{Liquid FW mean state}

- The model ensemble mean represents the canonical scenario of the Arctic liquid FW transport: The Arctic Ocean feeds liquid FW to the subpolar North Atlantic through both Davis and Fram Straits, and receives liquid FW through Bering Strait from the Pacific (Table 3, Figure 14). The models show slightly larger mean liquid FW export at Davis Strait than at Fram Strait.

- The simulated mean liquid FW export through Fram Strait is $-2123 \mathrm{~km}^{3} /$ year, at the lower bound of the synthesized value $\left(-2660 \pm 528 \mathrm{~km}^{3} /\right.$ year, Serreze et al., 2006). The liquid FW export at Davis Strait is $-3119 \mathrm{~km}^{3} /$ year and the inflow at Bering Strait is $2383 \mathrm{~km}^{3} /$ year in the model ensemble means, both of which are within the uncertainty range of the observations $(-3200 \pm$ 

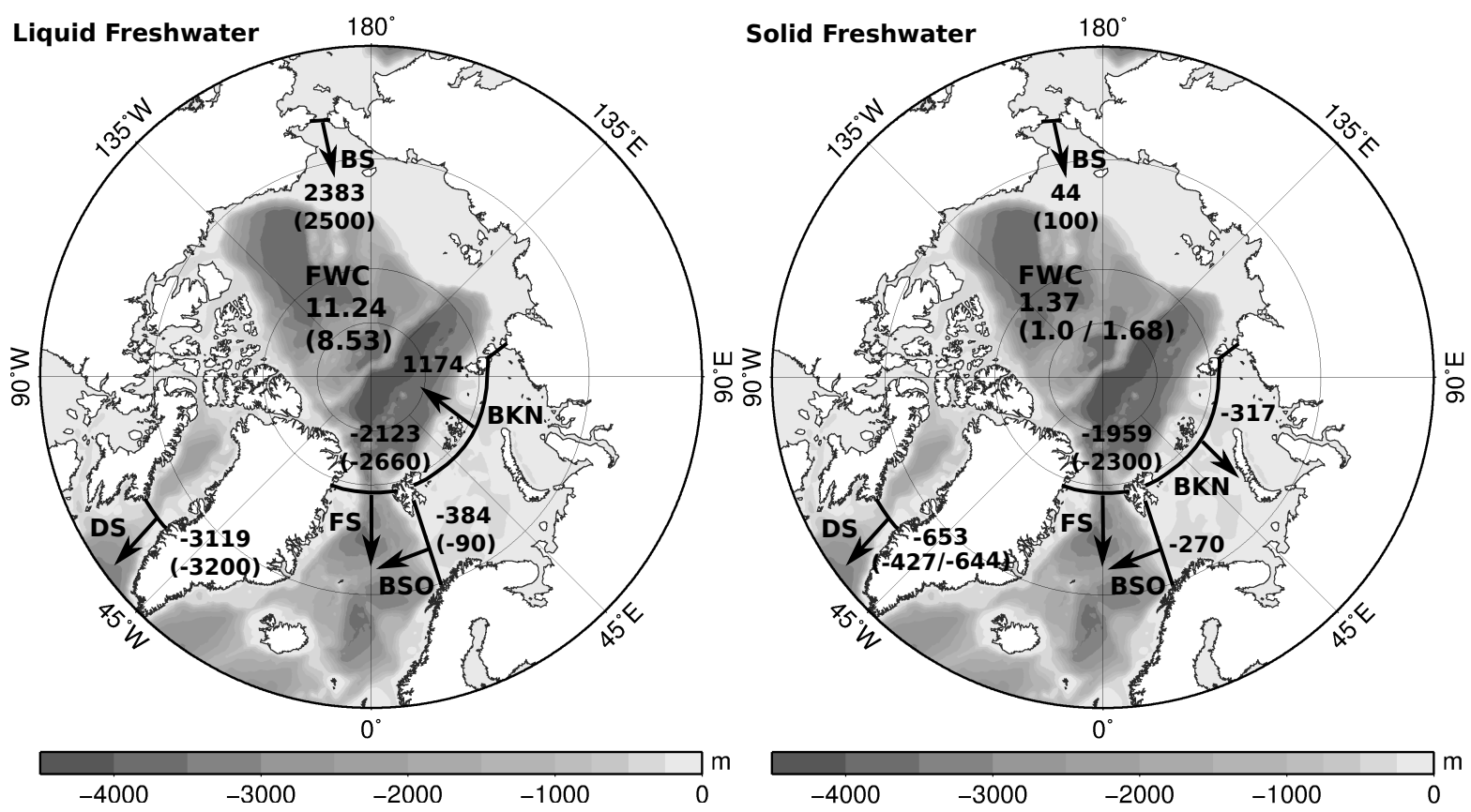

Figure 14: (left) Model ensemble mean of liquid freshwater budget of the Arctic Ocean. FW fluxes through the Arctic gateways are shown in $\mathrm{km}^{3} /$ year, and the FWC is in $10^{4} \mathrm{~km}^{3}$. The synthesized climatological values are shown in brackets; see Table 3 for their reference. The five main gateways are shown: Fram Strait (FS), Davis Strait (DS), Bering Strait (BS), Barents/Kara Seas northern boundary (BKN), and southern Barents Sea Opening (BSO). The last 30 model years (1978 - 2007) are used in the calculation. For a direct comparison the model ensemble mean of solid freshwater budget is shown on the right panel (taken from Figure 17 of Wang et al. (2015)). 
$320 \mathrm{~km}^{3}$ /year for Davis Strait (Serreze et al., 2006) and $2500 \pm 300 \mathrm{~km}^{3} /$ year for Bering Strait (Woodgate and Aagaard, 2005))

- The mean liquid FWC in the Arctic Ocean is $11.24 \times 10^{4} \mathrm{~km}^{3}$, higher than the value calculated from PHC3 climatology $\left(8.53 \times 10^{4} \mathrm{~km}^{3}\right.$, Steele et al., 2001). Fluxes due to SSS restoring supplied the source for the FWC increase during model spin-up (Appendix B).

\section{Liquid FW variability}

- The models well represent the observed interannual variability of liquid FW inflow at Bering Strait: an increase from 2001 to 2004, a drop in 2005 and then an upward trend again (Woodgate et al., 2012) (Figure 4). They also agree with the observations that there is no significant trend in the Bering Strait FW flux starting from 2001. The simulated seasonal variability is also very consistent to the observation.

- The liquid FW flux at Davis Strait has decreased from 1987-1990 to 2004-2010 by more than $1000 \mathrm{~km}^{3} /$ year (Curry et al., 2014). The model ensemble mean shows a descending trend as suggested by the observations, with a similar magnitude of difference between the two periods (Figure 4$]^{5}$

- The mean FW export at Fram Strait does not show persistent trend in the period of 2000s (Figure 4), consistent to the observations de Steur et al., 2009, 2014). The simulated changes at Fram Strait are smaller than at Davis Strait in the recent decades, in agreement with observations (Haine et al., 2015).

\footnotetext{
${ }^{5}$ Continuous observations in the eastern Parry Channel, the largest strait in the western CAA, have started since 2001 (Prinsenberg and Hamilton, 2005, Peterson et al. 2012). As the ocean FW transports through the two largest CAA straits (Parry Channel and Nares Strait) have similar interannual variability (Wekerle et al. 2013), the FW transport observed in the eastern Parry Channel can be used as an approximate reference to verify the simulated variation at Davis Strait. The FW export from Parry Channel has a descending trend from 2001 to 2007 in the mooring observations (Peterson et al., 2012), which is consistently shown by the model ensemble mean at Davis Strait (Figure 4). The descending trend has started since 1990 in the model simulation. This is supported by the result obtained from a "prediction model" that uses the relationship between the observed ocean transport and winds (Fig. 14 of Peterson et al. 2012.
} 
- The models simulate an upward trend in the Arctic liquid FWC starting from the mid-1990s (Figure 8), which was observed through in situ and satellite measurements (Proshutinsky et al., 2009; McPhee et al., 2009, Rabe et al., 2011; Giles et al., 2012; Polyakov et al., 2013; Rabe et al., 2014).

\section{Conclusion}

In this work we assessed the Arctic Ocean in 14 models participating in the Coordinated Ocean-ice Reference Experiments, phase II (CORE-II) intercomparison project.

All the models are global and the ocean-sea ice components of respective climate models (Danabasoglu et al., 2014). They used the same atmospheric forcing data sets and bulk formula following the CORE-II protocol (Griffies et al., 2012). The atmospheric forcing covers 60 years from 1948 to 2007 (Large and Yeager, 2009), and the models were run for 300 years corresponding to 5 consecutive loops of the 60 -year forcing period. Model configurations including resolution, parameterization, parameters are decided by the model developing groups.

We focused on the Arctic liquid FW sources and storage in this paper. The state of the model ensemble means is presented in Section 5. Other summaries are given below.

- The models are relatively good at representing the temporal variability of the total liquid FWC integrated over the Arctic Ocean, which is most pronounced on the decadal time scale (Figure 8). However, they have less skill in producing the observed changes in the FWC spatial distribution (Figure 10).

- Both the model spread and the interannual variability of liquid FW transport at the Bering and Davis Straits can be largely explained by the associated ocean volume transport (Figures 2 and 5). The models have good agreement for the interannual variability of liquid FW transport at these two gateways (Figure 4). The situation is very different at the Fram Strait and BKN, where salinity is very important in determining the variability of liquid FW transport as suggested in previous model studies (Lique et al., 2009; Jahn et al., 2010). Improving salinity representation in the Eurasian Basin and Barents/Kara Seas is required in order to better simulate the liquid FW transport at the latter two gateways. Overall, where the liquid 
FW transport variability is mainly determined by ocean volume transport, it is easier for the models to get consistent results because they usually have good skill in representing the variability of ocean volume transport. In contrast, if salinity variation is an important contributor, the models lack skills in representing FW transport because they commonly have a larger bias with salinity. The AOMIP models show a similar behaviour (Jahn et al., 2012).

- The models largely agree that the liquid surface FW flux and lateral FW transport contribute in phase to the decadal variation of liquid FWC. The upward trend in liquid FWC starting from the mid-1990s is induced by decreasing sea ice formation (positive surface FW flux anomaly) more than the reduction of liquid FW export in eight models among the ten models with these diagnostics available (Figure 9). On average the observed increasing trend of liquid FWC is underestimated by the models.

- On the seasonal time scale the variation of Arctic liquid FWC is predominantly determined by sea ice melting/freezing. The seasonal variability of liquid FW transport is consistently simulated at the Fram Strait and BKN (Figure 11), where the interannual variability lacks agreement (Figure 4). The good skill in representing the seasonality suggest that the signal of seasonal variation in salinity is well captured by the models, which is also shown in the AOMIP models (Jahn et al. 2012). The seasonality of liquid FW transport through Davis Strait shows more spread in the models than the interannual variability, implying that the variation of salt transport in the West Greenland Current plays a role in setting the total FW transport variability on the seasonal time scale at Davis Strait, as implied by observations (Curry et al., 2014).

Overall, the CORE-II models, driven by the same inter-annually varying atmospheric state, did not demonstrate qualitatively similar mean state in the Arctic Ocean, as also found for the North Atlantic (Danabasoglu et al., 2014). It is noticed that the model spread in the mean state of FW export into the North Atlantic is larger than its interannual variability magnitude. When we evaluate the model ensemble means of FW fluxes, 
it is found that both the mean state and variability are relatively well reproduced. The mean liquid FW fluxes are largely within the uncertainty range of available observations.

A common issue in the models is that the Arctic liquid FWC has a large positive bias, although it can reach equilibrium at the end of integrations in most of the models. is induced by the erosion of halocline and the bias in surface salinity (Appendix B). The FW fluxes through the Arctic gateways do not show trend associated with that of FWC (Figure 15), so the bias in the mean state of liquid FWC does not significantly deteriorate the mean state and variability of liquid FW transport. SSS restoring introduces artificial FW sources to the Arctic Ocean, and it tends to compensate part of the surface FW flux variability (Appendix C). The recent rapid increase of Arctic liquid FWC was damped by the restoring flux, although uncertainties in other FW sources possibly also contributed to the underestimation of the increasing trend in the FWC. It remains a research topic to minimize the impact of SSS restoring flux on local FW budget while retaining model stability in global ice-ocean simulations.

The model spread of mean FW fluxes is the largest at Davis Strait. The CAA straits cannot be explicitly resolved by the models, so their treatment needs to be adjusted, for example, according to observations of volume transport. Seemingly this is not commonly done for climate ocean models as some of those analyzed in this work. We also note that only refining horizontal spacing will not necessarily lead to more realistic liquid FW fluxes. For example, the $0.25^{\circ}$ model (MOM0.25) got too high liquid FW fluxes at Davis Strait. The fact that the straits are kept widened while the horizontal spacing is refined might have contribution to the overestimation of the FW transport. Bering Strait is also relatively narrow, only resolved with 1-4 grid cells in the coarse models. These narrow straits are among the regions where attention should be paid to ensure model fidelity.

We emphasize that the models have least agreement on the interannual variability of liquid FW fluxes at Fram Strait and the BKN among the Arctic gateways. Our analysis and previous studies (Lique et al., 2009; Jahn et al., 2010, 2012) lead to the same conclusion that the interannual variability of salinity upstream these gateways need to be improved. The disagreement in the liquid FW budget terms is large on decadal time scales among the models (Figure 9). In order to better compare and understand the roles 
of different FW sources, it is necessary to further improve their model representation.

MRI-A simulated the most realistic liquid FWC (and temperature and salinity, not shown) as expected for an assimilation system, but the mean FW fluxes through the Arctic gateways become worse than in its free-run counterpart MRI-F (Table 3). The variability of liquid FWC also become unrealistic. This indicates that reanalysis products should be used with caution because they do not necessarily outperform free-run models for all the important diagnostics.

At the end we would like to emphasize that observations available for verifying model results are still short in time and/or sparse in space. This is the case for both ocean and sea ice observations. Progress in model development will benefit from the observations currently being made and planned for the future.

\section{Acknowledgements}

The WCRP/CLIVAR Ocean Model Development Panel (OMDP) is responsible for organising the Coordinated Ocean-sea ice Reference Experiments, with support from the international CLIVAR and U.S. CLIVAR project offices. We are grateful for the efforts of modellers who have contributed to the simulation and processing of the CORE-II experiments. We thank Igor Polyakov for providing us with the FWC observational data. Comments by two reviewers and Claudia Wekerle, Richard Greatbatch and Tor Eldevik helped to improve the manuscript. Q. Wang is funded by the Helmholtz Climate Initiative REKLIM (Regional Climate Change) project. C. Roth was supported by the Co-Operative Project RACE-Regional Atlantic Circulation and Global Change funded by the German Federal Ministry for Education and Research (BMBF), grant no. 03F0651B. The work of P. Spence was supported by the Australian Research Council of Norway through the EarthClim (207711/E10) and NOTUR/NorStore projects, as well as the Centre for Climate Dynamics at the Bjerknes Centre for Climate Research. The CMCC contribution received funding from the Italian Ministry of Education, University, and Research and the Italian Ministry of Environment, Land, and Sea under the GEMINA project. NCAR is sponsored by the U. S.National Science Foundation (NSF). S.G. Yeager was supported by the NOAA Climate Program Office under Climate Variability 
and Predictability Program Grant NA09OAR4310163 and NA13OAR4310138 and by the NSF Collaborative Research EaSM2 grant OCE-1243015 to NCAR. The AWI-FESOM and Kiel-ORCA05 experiments were performed at the North-German Supercomputing Alliance (HLRN).

\section{Appendix A. Definition of freshwater content and transport}

The freshwater content (FWC) is the amount of zero-salinity water required to be taken out from the ocean or sea ice so that its salinity is changed to the chosen reference salinity. The Arctic liquid FWC is calculated as

$$
\iiint_{\Omega} \frac{S_{r e f}-S_{o}}{S_{r e f}} d V
$$

where the integration is taken over the Arctic domain (defined by Bering Strait, Fram Strait, Davis Strait, and the Barents and Kara Seas northern boundary (BKN), see Figure 1), $S_{o}$ is ocean salinity, and $S_{r e f}=34.8$ is the reference salinity. This reference value is widely used in studies on Arctic freshwater (e.g., Aagaard and Carmack, 1989; Serreze et al., 2006; Haine et al., 2015). If not otherwise mentioned, in this paper the integration in 1 is taken from ocean surface to depth $D(x, y)$ where the ocean salinity is equal to the reference salinity.

We will also compare the vertically integrated FWC at each horizontal grid cell, which is

$$
\int_{D(x, y)}^{\text {surface }} \frac{S_{r e f}-S_{o}}{S_{r e f}} d h
$$

Liquid freshwater transport through a gateway is defined as

$$
\iint_{\mathrm{S}} \frac{S_{r e f}-S_{o}}{S_{r e f}} v_{n} d s
$$

where the integration is taken over the vertical section area $\mathrm{S}, v_{n}$ is the ocean velocity normal to the transect. Equation 3 can be written as

$$
\iint_{\mathrm{S}} \frac{S_{r e f}-S_{o}}{S_{r e f}} v_{n} d s=\iint_{\mathrm{S}} v_{n} d s-\frac{1}{S_{r e f}} \iint_{\mathrm{S}} S_{o} v_{n} d s
$$

On the right hand side, the first term is ocean volume transport and the second term is salt transport normalized by the reference salinity. 


\section{Appendix B. Model spin-up and drift}

Model spin-up

In the analysis of the CORE-II models for the North Atlantic, it was shown that 5 loops are sufficient for more than half of the models to reach equilibrium with respect to a key diagnostic, the Atlantic Meridional Overturning Circulation (AMOC) maximum (Danabasoglu et al., 2014). Here we will examine if the models achieved equilibrium in the Arctic Ocean. We choose two important diagnostics to evaluate the spinup of the ocean: the liquid freshwater content (FWC) and the total liquid freshwater (FW) flux from the Arctic Ocean to the subpolar North Atlantic.
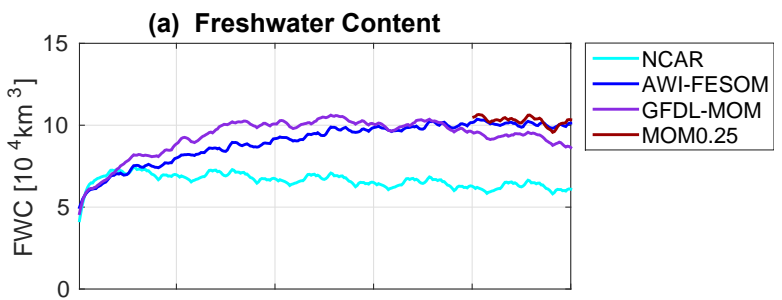

(b) Freshwater Export to Atlantic
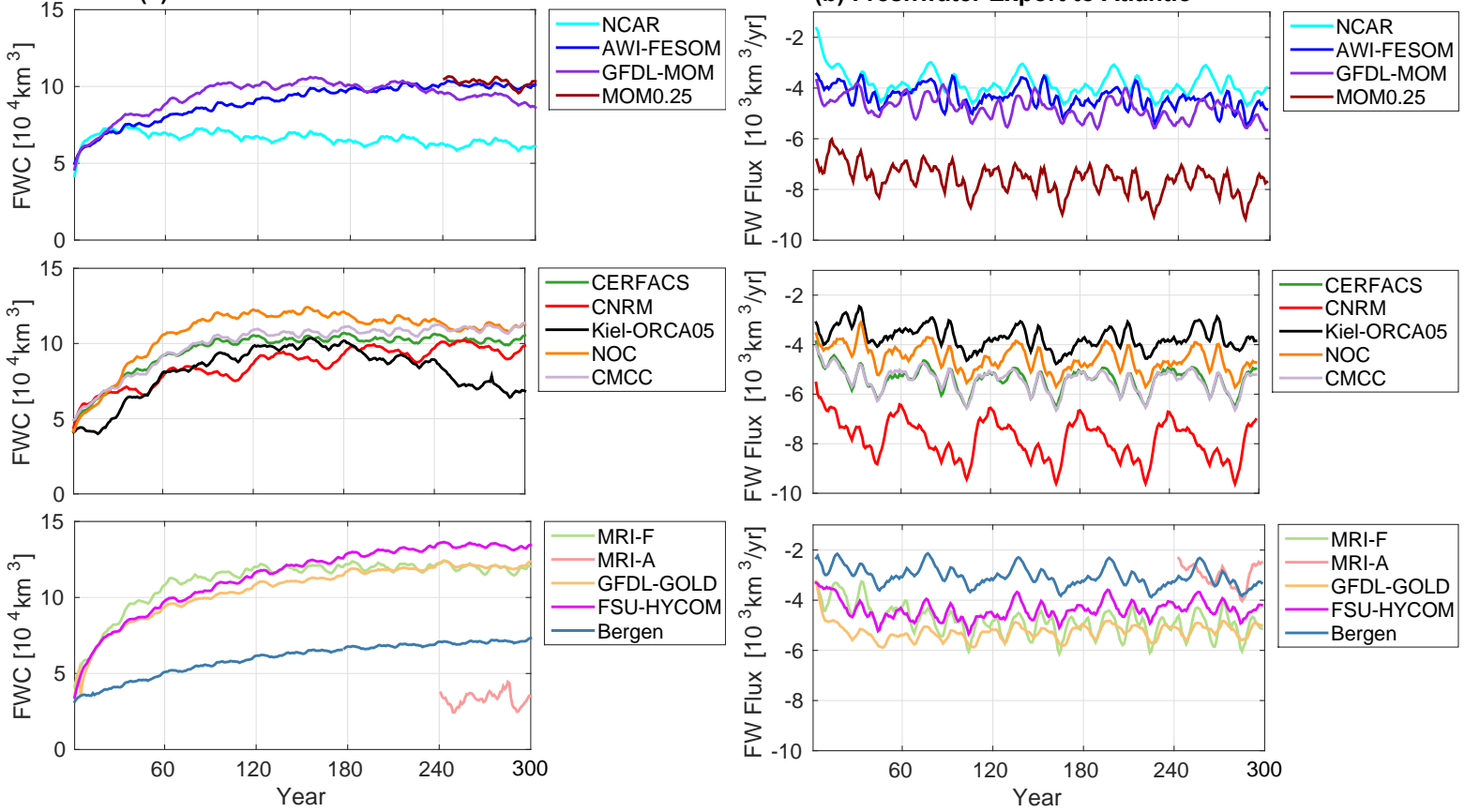

Figure 15: (a) Annual mean Arctic liquid freshwater content (FWC) for the entire 300-yr integration length. The FWC is integrated from ocean surface to bottom over the Arctic domain. (b) Five years running mean Arctic freshwater (FW) export fluxes to the North Atlantic, that is, the sum of FW fluxes through Davis Strait and Fram Strait. Each 60-yr loop, corresponding to calendar years 1948-2007, is indicated by the vertical grid lines. FWC data for MOM0.25 is only available for the last loop. The MRI-A experiment is only done for the last loop, which starts after a 10 years transition simulation from the end of the MRI-F 4th loop.

Figure 15 a shows the Arctic liquid FWC time series for the 300 years simulations. The FWC in this figure is calculated by integrating 1 from ocean surface to bottom over the 
Arctic domain. As all models start from the climatological hydrography, the liquid FWCs in different models are quite similar at the beginning. They increase rapidly during the first model loop in most of the models, and the most rapid increase takes place during the first decade. Although the FWCs have increasing tendency in the first few decades, they decrease in four models after the increasing phase, including NCAR, GFDL-MOM, NOC and Kiel-ORCA05. Among these models the NCAR model starts to show descending trend the earliest, after about 30 model years.

(a) Liquid freshwater content
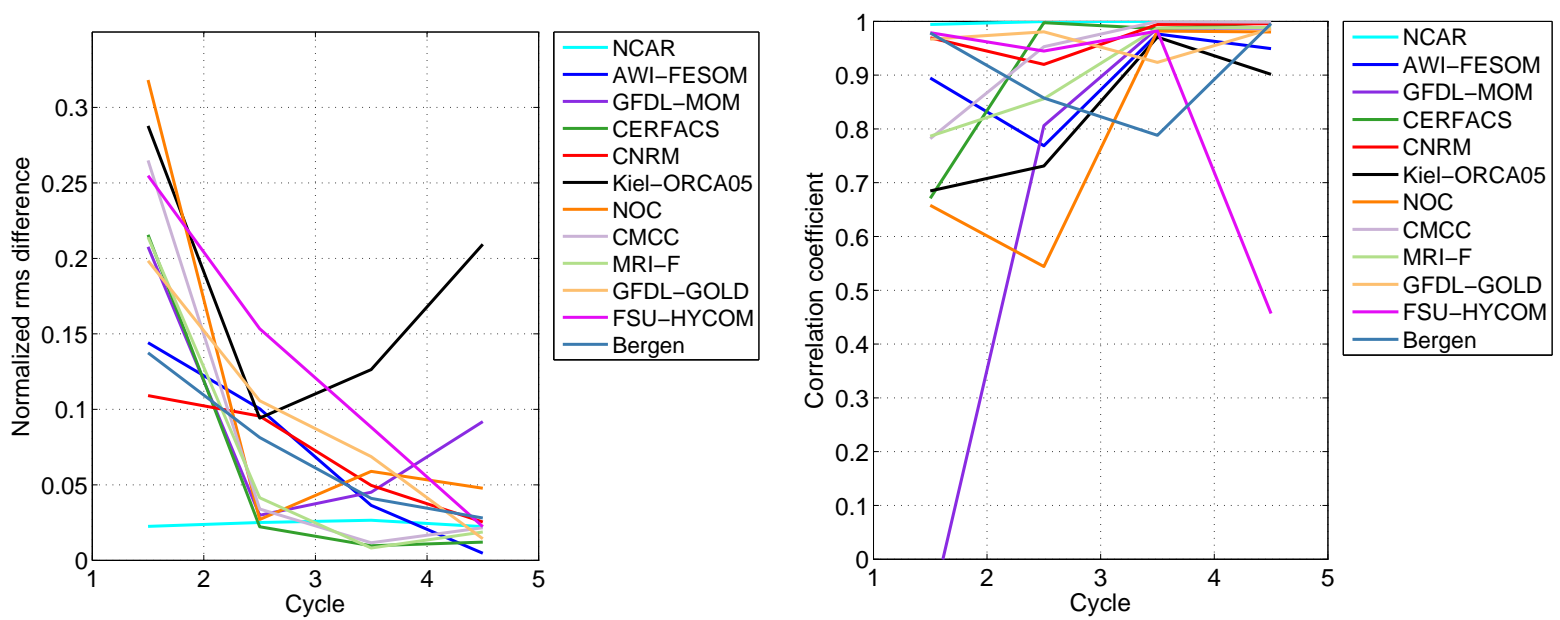

(b) Liquid freshwater transport
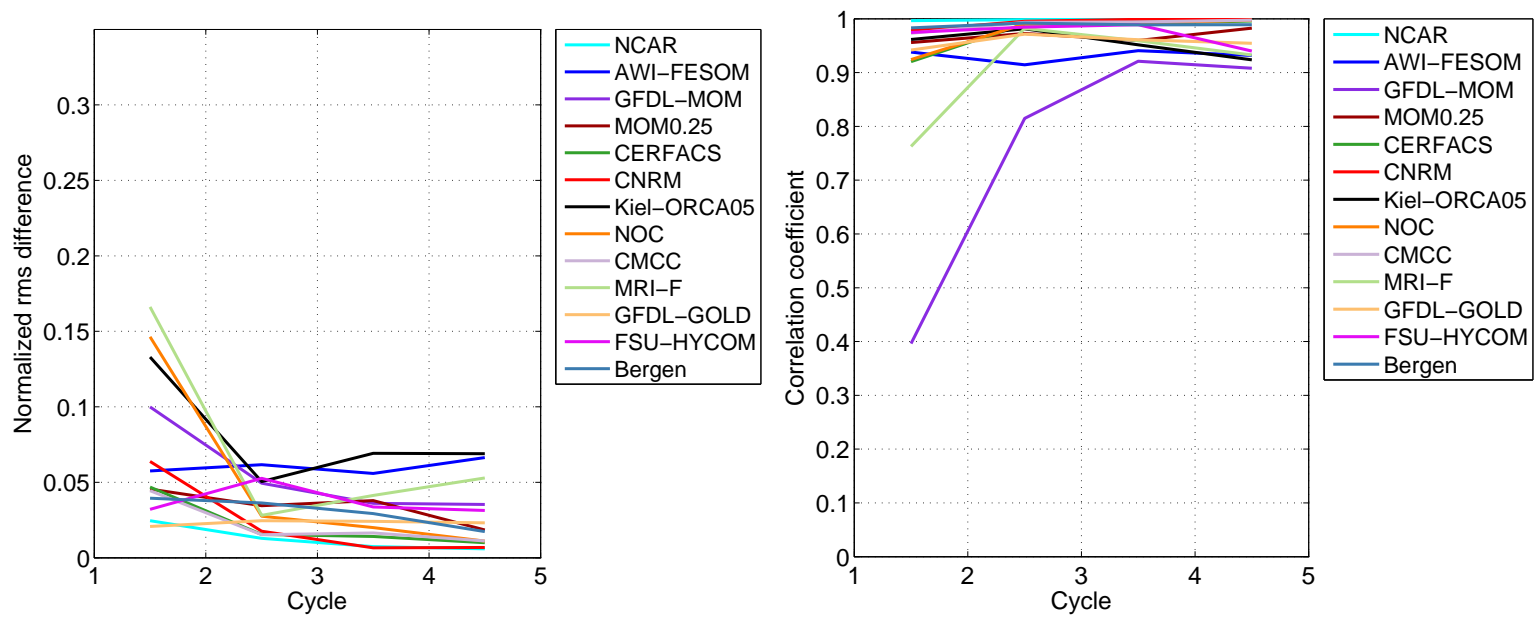

Figure 16: Convergence of (a) Arctic freshwater content and (b) freshwater export to the North Atlantic. Left (right) panels show the RMS difference (correlation coefficients) between two consecutive loops. The period of 1978 - 2007 in each loop is used in the calculation. Results for a few models are missing for the reasons mentioned in the caption of Figure 15

We take the same measure as in the AMOC CORE-II paper (Danabasoglu et al., 2014) to illustrate whether the models reach equilibrium at the end of the experiments. 
The root-mean-square (RMS) difference and the correlation coefficients between two sequential loops are calculated and shown in Figure 16a. The RMS difference is normalized by the mean FWC of all models. The RMS difference drops quickly during the first three loops. Except for Kiel-ORCA05 and GFDL-MOM, which have increasing RMS difference after the third loop, other models have RMS difference less than $5 \%$ of the ensemble mean liquid FWC at the end. The correlation between sequential loops increases with time on average, although most of the models show oscillations in the magnitude of the correlation coefficients. Except for FSU-HYCOM, which has a significant drop with the correlation coefficient, the models have correlation coefficients larger than 0.9 at the end.

Another quantity we choose to check for equilibrium is the total liquid FW transport from the Arctic Ocean to the North Atlantic. The sum of the FW fluxes through Fram and Davis Straits is plotted in Figure 15b. Although the models have very large spread in the magnitude of liquid FW transport, they do not have substantial descending or ascending trend throughout the 300 years simulations. The model convergence with respect to the liquid FW fluxes is shown in Figure 16b. On average, the normalized RMS difference between the first two loops is smaller than that for the liquid FWC, and reaches quasi-equilibrium faster. The correlation between sequential loops for the liquid freshwater flux is more than 0.9 throughout the experiments for all models except for GFDL-MOM and MRI-F, which have low values for the first few loops.

As indicated by the convergence of Arctic liquid FWC and FW transport, most of the models can reach equilibrium within 5 loops. Convergence analysis was also made for solid FWC and FW transport, and they show better convergence than their liquid counterparts (not shown). Note that the Arctic Ocean is not only a reservoir of FW, but also a northern terminate of North Atlantic Current, which brings saltier Atlantic Water to the Arctic Ocean. Therefore the total Arctic liquid FWC (integrated from ocean surface to bottom) can also be influenced by the Atlantic inflow. The descending trend of Arctic liquid FWC in the last two loops in Kiel-ORCA05 (Figure 15a) can be explained by the Atlantic Water inflow, which is associated with an upward trend in its simulated AMOC (see the CORE-II North Atlantic results described by Danabasoglu et al., 2014). When we calculate the FWC only for the upper ocean above the Atlantic Water layer, then there is no descending trend in the FWC in Kiel-ORCA05 (not shown). 
The Atlantic Water layer in the Arctic Ocean simulated in CORE-II models is studied in Ilicak et al. (2015).

Model drift in salinity
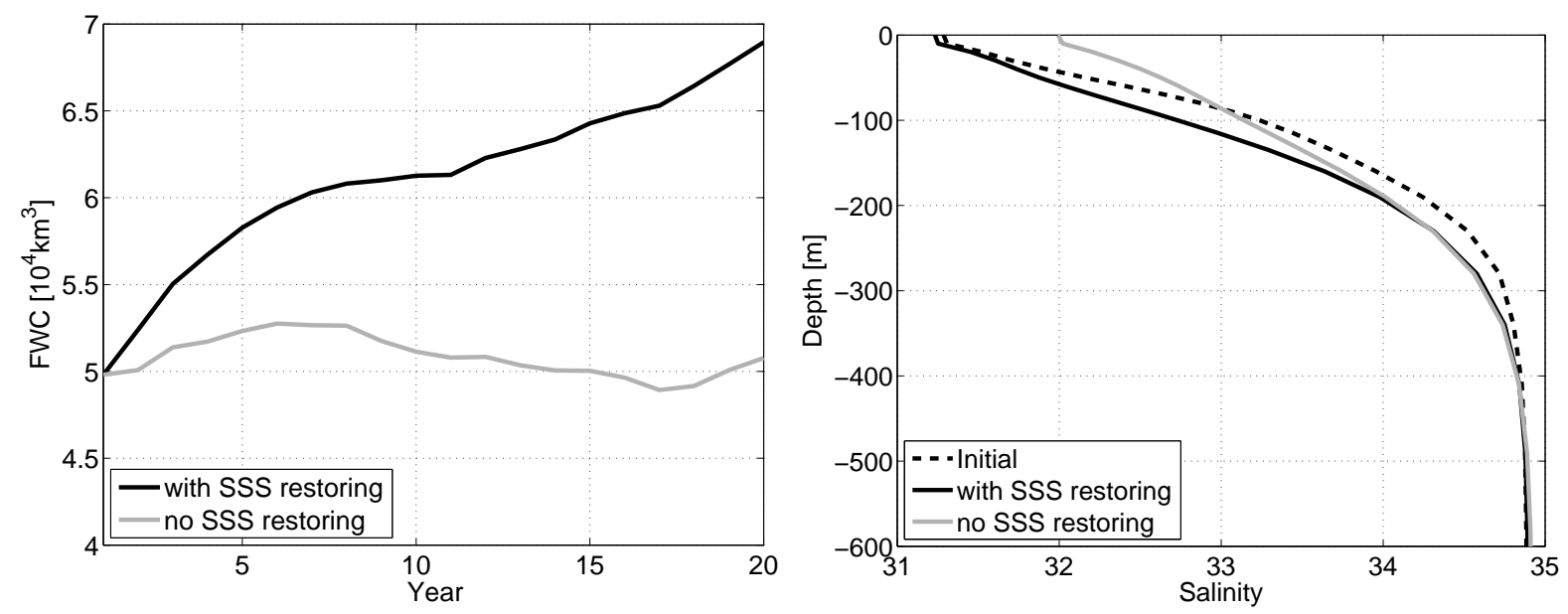

Figure 17: (left) Annual mean liquid FWC simulated in FESOM. The time series compare the FWC in two simulations when sea surface salinity (SSS) restoring is switched on and off. The FWC is integrated from ocean surface to bottom over the Arctic domain. (right) Zonal mean salinity profiles averaged in the Arctic basin at the beginning of the simulations (dashed line) and after 20 years (solid lines).

Most of the models tend to simulate a much fresher Arctic Ocean than that suggested by climatological hydrography (Figure 15 a). Such a similar model behaviour indicates a possible common cause. We carried out one sensitivity experiment with FESOM to better understand the process related to the simulated liquid FWC trend. In this experiment we switched off the sea surface salinity (SSS) restoring and ran the model for 20 years starting from climatological hydrography. When SSS restoring is switched off, the rapid increasing trend of FWC disappears (Figure 17(left)). In the case without SSS restoring, the model has a positive salinity drift near the ocean surface and a negative drift between about $100-400 \mathrm{~m}$ depth (Figure 17(right)). When the SSS restoring is switched on, it corrects the near surface salinity drift and the surface salinity is maintained close to the climatology as expected. This correction acts effectively to increase the volume-integrated FWC.

Nguyen et al. (2009) proposed an explanation for model salinity drift in Arctic Ocean following the experience of modelling Southern Ocean described by Duffy et al. (1999). 
They found that if salt rejected during ice formation is added to the ocean at the surface,

the static instability in the model will initialize strong vertical mixing and weaken the vertical salinity gradient, resulting in negative salinity anomaly in the halocline and positive salinity anomaly at the ocean surface. By distributing rejected salt in the ocean column with some vertical distribution function and reducing the vertical mixing coefficient, they got significantly improved salinity profiles. It remains to see if the common issue of upper ocean salinity drift and FWC trend in the CORE-II models can be alleviated when adequate parameterizations of salt rejection are used.

\section{Appendix C. Interannual variability of restoring flux}

The changing rate of Arctic liquid FWC is determined by the lateral fluxes through the gateways and the vertical FW flux at ocean surface. The anomalies of (annual mean) surface FW flux, surface restoring FW flux, the sum of liquid FW transport through all Arctic gateways, and the time derivative (the changing rate) of liquid FWC are shown in Figure 18, The FW fluxes used to restore SSS toward climatology play an important role in tuning the contribution of FW sources to the changing rate of liquid FWC. In a few models, including AWI-FESOM, GFDL-MOM, MOM0.25, MRI-F and Bergen, the restoring FW flux anti-correlates with surface FW flux significantly, and many pronounced events of surface $\mathrm{FW}$ variation are partly compensated by restoring fluxes, especially in the last 15 years. The restoring FW flux in Kiel-ORCA05 has the weakest variability, because it is not applied under sea ice, which covers a major part of the Arctic Ocean. Therefore, the changing rate of liquid FWC in this model shows a large variation of the surface FW flux. The models agree that surface and restoring FW fluxes vary most significantly on interannual time scales, while the lateral FW transport has large variation on decadal time scales, the same as shown in previous model studies (Köberle and Gerdes, 2007). Over the last 15 years, most of the models show positive anomaly for the surface FW flux, with large interannual variability overlaid. 

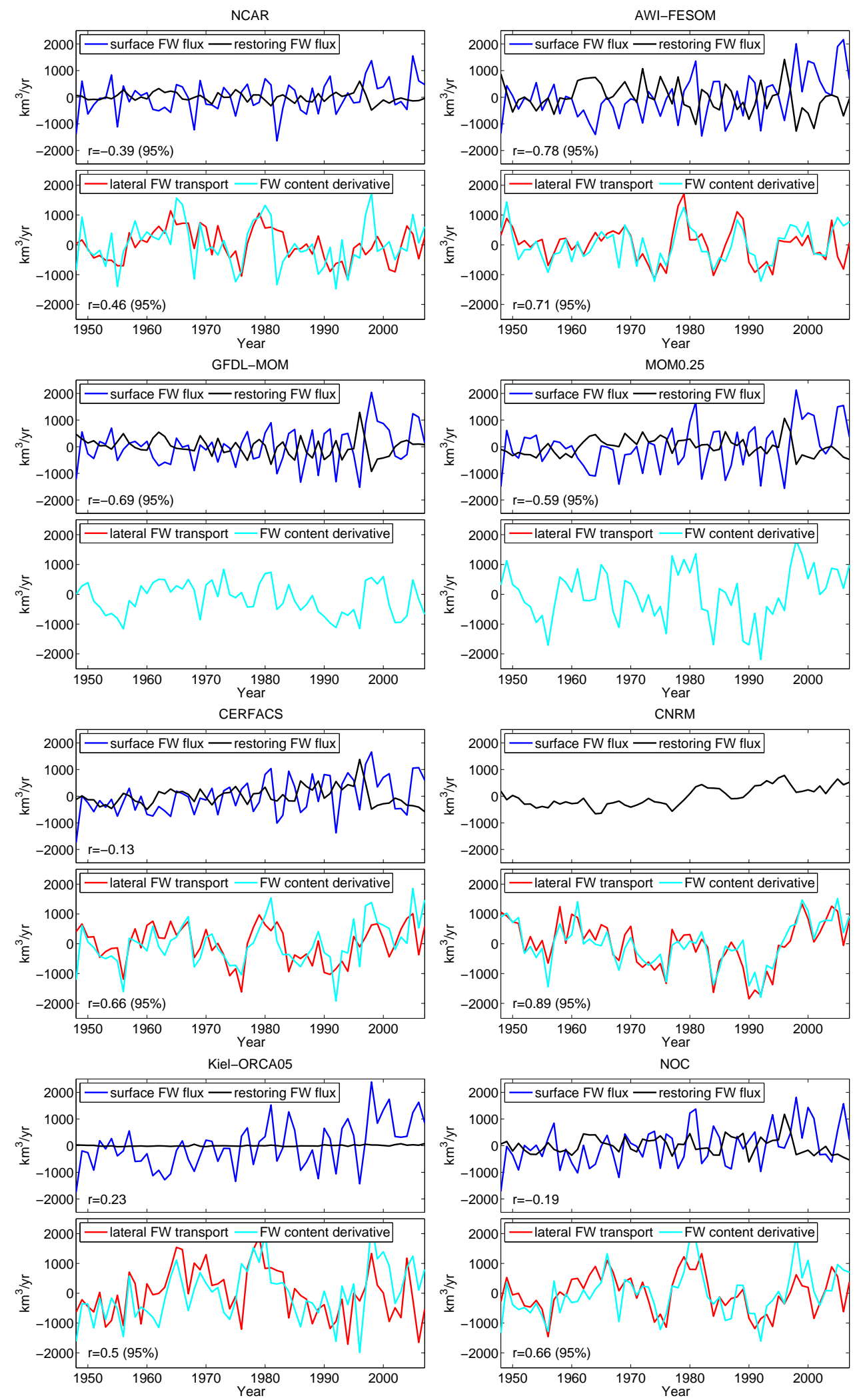

Figure 18: Variability of liquid FW budget. The correlation coefficients between each two curves are shown in every panel, and the $95 \%$ confidence level is indicated when the correlation is significant at this level. Surface FW flux data for CNRM and BKN and FW transport data in MOM and GOLD are unavailable. Positive values mean source for the Arctic Ocean. 

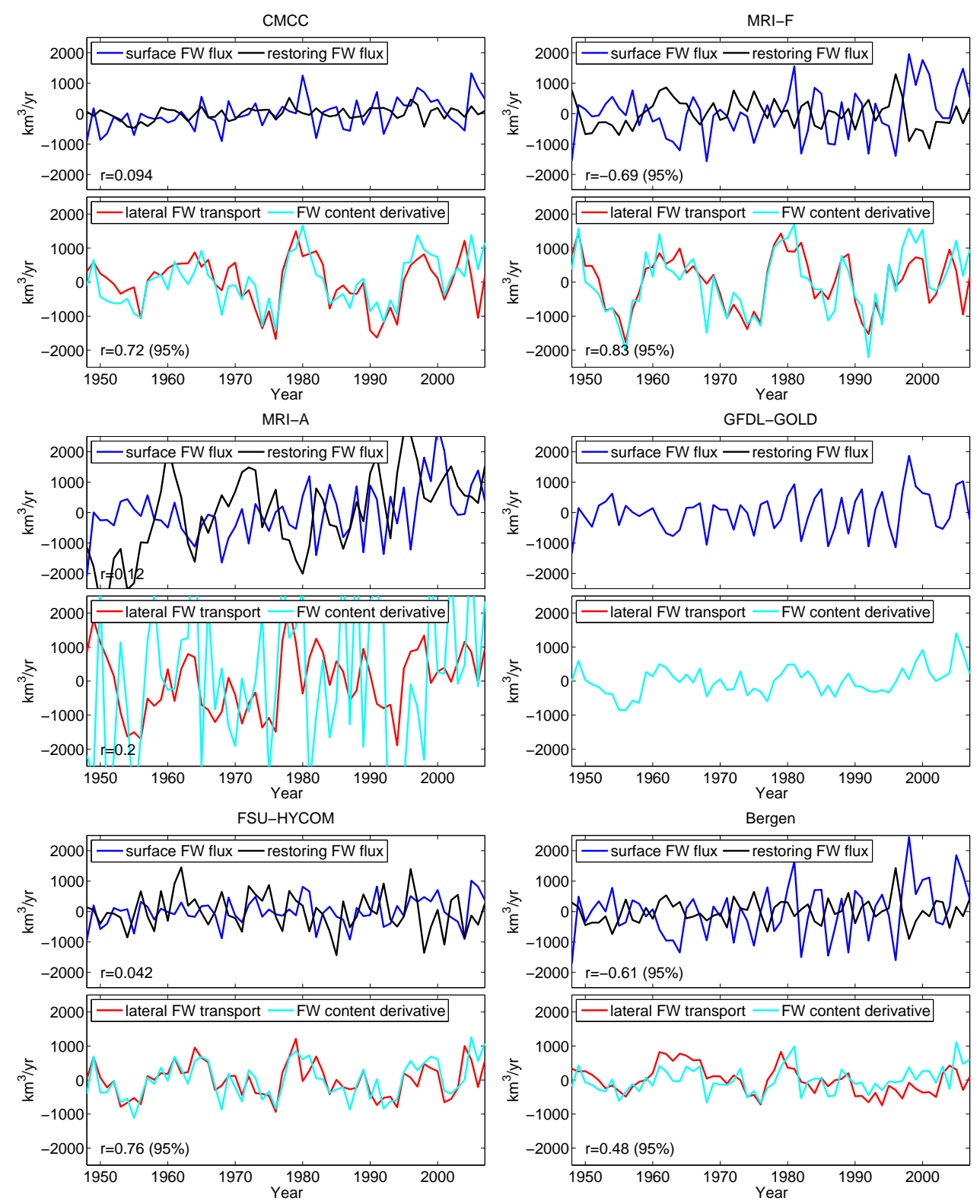

Figure 18: (continued) Variability of liquid freshwater budget. The correlation coefficient between each two curves is shown in every panel, and the $95 \%$ confidence level is indicated when the correlation is significant at this level. Surface FW flux data for CNRM and BKN and FW transport data in MOM and GOLD are unavailable. Positive values mean source for the Arctic Ocean. 


\section{References}

Aagaard, K., Carmack, E.C., 1989. The role of sea ice and other fresh-water in the Arctic circulation. J. Geophys. Res. 94, 14485-14498.

Aagaard, K., Swift, J.H., Carmack, E., 1985. Thermohaline circulation in the Arctic mediterranean seas. Journal of Geophysical Research-oceans 90, 4833-4846.

Arthun, M., Eldevik, T., Smedsrud, L.H., Skagseth, O., Ingvaldsen, R.B., 2012. Quantifying the Influence of Atlantic Heat on Barents Sea Ice Variability and Retreat. Journal of Climate 25, 4736-4743.

Beszczynska-Moeller, A., Woodgate, R.A., Lee, C., Melling, H., Karcher, M., 2011. A Synthesis of Exchanges Through the Main Oceanic Gateways to the Arctic Ocean. Oceanography 24, 82-99.

Cuny, J., Rhines, P.B., Kwok, R., 2005. Davis Strait volume, freshwater and heat fluxes. Deep-sea Research Part I-oceanographic Research Papers 52, 519-542.

Curry, B., Lee, C.M., Petrie, B., Moritz, R.E., Kwok, R., 2014. Multiyear volume, liquid freshwater, and sea ice transports through Davis Strait, 2004-2010. Journal of Physical Oceanography 44, 1244-1266.

Danabasoglu, G., Yeager, S.G., Bailey, D., Behrens, E., Bentsen, M., Bi, D., Biastoch, A., Böning, C., Bozec, A., Canuto, V.M., Cassou, C., Chassignet, E., Coward, A.C., Danilov, S., Diansky, N., Drange, H., Farneti, R., Fernandez, E., Fogli, P.G., Forget, G., Fujii, Y., Griffies, S.M., Gusev, A., Heimbach, P., Howard, A., Jung, T., Kelley, M., Large, W.G., Leboissetier, A., Lu, J., Madec, G., Marsland, S.J., Masina, S., Navarra, A., Nurser, A.G., Pirani, A., y Melia, D.S., Samuels, B.L., Scheinert, M., Sidorenko, D., Treguier, A.M., Tsujino, H., Uotila, P., Valcke, S., Voldoire, A., Wang, Q., 2014. North Atlantic simulations in Coordinated Ocean-ice Reference Experiments phase $\{$ II $\}$ (CORE-II). part i: Mean states. Ocean Modelling 73, 76 - 107. 
Danabasoglu, G., Yeager, S.G., Bailey, D., Behrens, E., Bentsen, M., Bi, D., Biastoch, A., Böning, C., Bozec, A., Canuto, V.M., Cassou, C., Chassignet, E., Coward, A.C., Danilov, S., Diansky, N., Drange, H., Farneti, R., Fernandez, E., Fogli, P.G., Forget, G., Fujii, Y., Griffies, S.M., Gusev, A., Heimbach, P., Howard, A., Jung, T., Kelley, M., Large, W.G., Leboissetier, A., Lu, J., Madec, G., Marsland, S.J., Masina, S., Navarra, A., Nurser, A.G., Pirani, A., y Melia, D.S., Samuels, B.L., Scheinert, M., Sidorenko, D., Treguier, A.M., Tsujino, H., Uotila, P., Valcke, S., Voldoire, A., Wang, Q., 2015. North Atlantic simulations in Coordinated Ocean-ice Reference Experiments phase $\{$ II $\}$ (CORE-II). part ii: Inter-annual to decadal variability. Ocean Modelling , submitted.

Dickson, R., Rudels, B., Dye, S., Karcher, M., Meincke, J., Yashayaev, I., 2007. Current estimates of freshwater flux through Arctic and subarctic seas. Prog. Oceanogr. 73, $210-230$.

Duffy, P.B., Eby, M., Weaver, A.J., 1999. Effects of sinking of salt rejected during formation of sea ice on results of an ocean-atmosphere-sea ice climate model. Geophysical Research Letters 26, 1739-1742.

Giles, K.A., Laxon, S.W., Ridout, A.L., Wingham, D.J., Bacon, S., 2012. Western Arctic Ocean freshwater storage increased by wind-driven spin-up of the Beaufort Gyre. Nature Geoscience 5, 194-197.

Goosse, H., Fichefet, T., Campin, J.M., 1997. The effects of the water flow through the Canadian Archipelago in a global ice-ocean model. Geophysical Research Letters 24, $1507-1510$.

Griffies, S., Winton, M., Samuels, B., Danabasoglu, G., Yeager, S., Marlsand, S., Drange, H., Bentsen, M., 2012. Datasets and protocol for the CLIVAR WGOMD Coordinated Ocean-sea ice Reference Experiments (COREs). Technical Report 21. WCRP Report.

Griffies, S.M., Biastoch, A., Böning, C., Bryan, F., Danabasoglu, G., Chassignet, E.P., England, M.H., Gerdes, R., Haak, H., Hallberg, R.W., Hazeleger, W., Jungclaus, J., Large, W.G., Madec, G., Pirani, A., Samuels, B.L., Scheinert, M., Gupta, A.S., Sev- 
erijns, C.A., Simmons, H.L., Treguier, A.M., Winton, M., Yeager, S., Yin, J., 2009.

Griffies, S.M., Yin, J., Durack, P.J., Goddard, P., Bates, S.C., Behrens, E., Bentsen, M., Bi, D., Biastoch, A., Boening, C.W., Bozec, A., Chassignet, E., Danabasoglu, G., Danilov, S., Domingues, C.M., Drange, H., Farneti, R., Fernandez, E., Greatbatch, R.J., Holland, D.M., Ilicak, M., Large, W.G., Lorbacher, K., Lu, J., Marsland, S.J., Mishra, A., Nurser, A.J.G., Salas y Melia, D., Palter, J.B., Samuels, B.L., Schroeter, J., Schwarzkopf, F.U., Sidorenko, D., Treguier, A.M., Tseng, Y.h., Tsujino, H., Uotila, P., Valcke, S., Voldoire, A., Wang, Q., Winton, M., Zhang, X., 2014. An assessment of global and regional sea level for years 1993-2007 in a suite of interannual CORE-II simulations. Ocean Modelling 78, 35-89.

Haine, T., Curry, B., Gerdes, R., Hansen, E., Karcher, M., Lee, C., Rudels, B., Spreen, G., de Steur, L., Stewart, K., Woodgate, R., 2015. Arctic freshwater export: Status, mechanisms, and prospects. Global and Planetary Change 125, 13 - 35.

Hakkinen, S., 1999. A simulation of thermohaline effects of a great salinity anomaly. Journal of Climate 12, 1781-1795.

Holland, M.M., Finnis, J., Barrett, A.P., Serreze, M.C., 2007. Projected changes in Arctic Ocean freshwater budgets. Journal of Geophysical Research-biogeosciences 112, G04S55.

Ilicak, M., Drange, H., Wang, Q., Gerdes, R., et al., 2015. An assessment of the Arctic Ocean in a suite of interannual CORE-II simulations. Part III: Hydrohraphy and fluxes. Ocean Modell. , under revision.

Jahn, A., Aksenov, Y., de Cuevas, B.A., de Steur, L., Hakkinen, S., Hansen, E., Herbaut, C., Houssais, M..N., Karcher, M., Kauker, F., Lique, C., Nguyen, A., Pemberton, P., Worthen, D., Zhang, J., 2012. Arctic Ocean freshwater: How robust are model simulations? J. Geophys. Res. - Oceans 117, C00D16.

Jahn, A., Tremblay, L.B., Newton, R., Holland, M.M., Mysak, L.A., Dmitrenko, I.A., 
2010. A tracer study of the Arctic Ocean's liquid freshwater export variability. J. Geophys. Res. - Oceans 115, C07015.

Jungclaus, J.H., Haak, H., Latif, M., Mikolajewicz, U., 2005. Arctic-North Atlantic interactions and multidecadal variability of the meridional overturning circulation. Journal of Climate 18, 4013-4031.

Kinney, J., Maslowski, W., Aksenov, Y., de Cuevas, B., Nguyen, A., Osinski, R., Steele, M., Woodgate, R., Zhang, J., 2014. On the flow through Bering Strait: a synthesis of model results and observations, in: Grebmeier, J. (Ed.), The Pacific-Arctic Region: ecosystem status and trends in a rapidly changing environment, Springer. pp. 167-198.

Köberle, C., Gerdes, R., 2007. Simulated variability of the Arctic Ocean freshwater balance 1948-2001. Journal of Physical Oceanography 37, 1628-1644.

Koldunov, N.V., Serra, N., Köhl, A., Stammer, D., Henry, O., Cazenave, A., Prandi, P., Knudsen, P., Andersen, O.B., Gao, Y., Johannessen, J., 2014. Multimodel simulations of Arctic Ocean sea surface height variability in the period 1970-2009. Journal of Geophysical Research: Oceans 119, 8936-8954.

Komuro, Y., Hasumi, H., 2005. Intensification of the Atlantic deep circulation by the Canadian Archipelago throughflow. Journal of Physical Oceanography 35, 775-789.

Large, W.G., Yeager, S.G., 2009. The global climatology of an interannually varying air-sea flux data set. Climate Dynamics 33, 341-364.

Lique, C., Treguier, A.M., Scheinert, M., Penduff, T., 2009. A model-based study of ice and freshwater transport variability along both sides of Greenland. Climate Dynamics $33,685-705$.

McPhee, M.G., Proshutinsky, A., Morison, J.H., Steele, M., Alkire, M.B., 2009. Rapid change in freshwater content of the Arctic Ocean. Geophysical Research Letters 36, L10602.

Melling, H., 2000. Exchanges of freshwater through the shallow straits of the North 
American Arctic, in: Lewis, E.L.e.a. (Ed.), The Freshwater Budget of the Arctic Ocean, Springer, New York. pp. 479-502.

Morison, J., Kwok, R., Peralta-Ferriz, C., Alkire, M., Rigor, I., Andersen, R., Steele, M., 955 2012. Changing Arctic Ocean freshwater pathways. Nature 481, 66-70.

Nguyen, A.T., Menemenlis, D., Kwok, R., 2009. Improved modeling of the Arctic halocline with a subgrid-scale brine rejection parameterization. J. Geophys. Res. - Oceans 114, C11014.

Penduff, T., Le Sommer, J., Barnier, B., Treguier, A.M., Molines, J.M., Madec, G., 2007. Influence of numerical schemes on current-topography interactions in $1 / 4^{\circ}$ global ocean simulations. Ocean Sci. 3, 509-524.

Peterson, I., Hamilton, J., Prinsenberg, S., Pettipas, R., 2012. Wind-forcing of volume transport through Lancaster Sound. Journal of Geophysical Research-oceans 117, C11018.

Polyakov, I.V., Alexeev, V.A., Belchansky, G.I., Dmitrenko, I.A., Ivanov, V.V., Kirillov, S.A., Korablev, A.A., Steele, M., Timokhov, L.A., Yashayaev, I., 2008. Arctic ocean freshwater changes over the past 100 years and their causes. J. Climate 21, 364-384.

Polyakov, I.V., Bhatt, U.S., Walsh, J.E., Abrahamsen, E.P., Pnyushkov, A.V., Wassmann, P.F., 2013. Recent oceanic changes in the Arctic in the context of long-term observations. Ecological Applications 23, 1745-1764.

Prinsenberg, S.J., Hamilton, J., 2005. Monitoring the volume, freshwater and heat fluxes passing through Lancaster Sound in the Canadian Arctic Archipelago. Atmosphereocean $43,1-22$.

Proshutinsky, A., Bourke, R.H., McLaughlin, F.A., 2002. The role of the Beaufort Gyre in Arctic climate variability: Seasonal to decadal climate scales. Geophysical Research Letters 29, 2100.

Proshutinsky, A., Krishfield, R., Timmermans, M.L., Toole, J., Carmack, E., McLaughlin, F., Williams, W.J., Zimmermann, S., Itoh, M., Shimada, K., 2009. Beaufort Gyre 
freshwater reservoir: State and variability from observations. Journal of Geophysical Research-oceans 114, C00A10.

Rabe, B., Dodd, P., Hansen, E., Falck, E., Schauer, U., Mackensen, A., BeszczynskaMöller, A., Kattner, G., Rohling, E.J., Cox, K., 2013. Export of Arctic freshwater components through the Fram Strait 1998-2011. Ocean Sci. 9, 91-109.

Rabe, B., Karcher, M., Kauker, F., Schauer, U., Toole, J.M., Krishfield, R.A., Pisarev, S., Kikuchi, T., Su, J., 2014. Arctic ocean basin liquid freshwater storage trend 1992-2012. Geophysical Research Letters 41, 961-968.

Rabe, B., Karcher, M., Schauer, U., Toole, J.M., Krishfield, R.A., Pisarev, S., Kauker, F., Gerdes, R., Kikuchi, T., 2011. Assessment of Arctic Ocean freshwater content changes from the 1990s to the 2006-2008 period. Deep-sea Research Part I-oceanographic Research Papers 58, 173-185.

Rabe, B., Schauer, U., Mackensen, A., Karcher, M., Hansen, E., Beszczynska-Moeller, A., 2009. Freshwater components and transports in the Fram Strait - recent observations and changes since the late 1990s. Ocean Science 5, 219-233.

Roach, A.T., Aagaard, K., Pease, C., Salo, S.A., Weingartner, T., Pavlov, V., Kulakov, M., 1995. Direct measurements of transport and water properties through the Bering Strait. Journal of Geophysical Research-Oceans 100, 18443-18457.

Schauer, U., Beszczynska-Moeller, A., Walczowski, W., Fahrbach, E., Piechura, J., Hansen, E., 2008. Variation of measured heat flow through the Fram Strait between 1997 and 2006, in: Dickson, R.e.a. (Ed.), Arctic-Subarctic Ocean Fluxes: Defining the Role of the Northern Seas in Climate, Springer. pp. 65-85.

Serreze, M.C., Barrett, A.P., Slater, A.G., Woodgate, R.A., Aagaard, K., Lammers, R.B., Steele, M., Moritz, R., Meredith, M., Lee, C.M., 2006. The large-scale freshwater cycle of the Arctic. J. Geophys. Res. - Oceans 111, C11010.

Skagseth, O.and Furevik, T., Ingvaldsen, R., Mork, H.L.K., Orvik, K., Ozhigi, V., 2008. Volume and heat transports to the Arctic Ocean via the Norwegian and Barents Seas, 
in: Dickson, R.e.a. (Ed.), Arctic-Subarctic Ocean Fluxes: Defining the Role of the Northern Seas in Climate, Springer. pp. 45-64.

Smedsrud, L.H., Esau, I., Ingvaldsen, R.B., Eldevik, T., Haugan, P.M., Li, C., Lien, V.S., Olsen, A., Omar, A.M., Ottera, O.H., Risebrobakken, B., Sando, A.B., Semenov, V.A., Sorokina, S.A., 2013. The role of the Barents Sea in the Arctic climate system. Reviews of Geophysics 51, 415-449.

Smedsrud, L.H., Ingvaldsen, R., Nilsen, J.E.O., Skagseth, O., 2010. Heat in the Barents Sea: transport, storage, and surface fluxes. Ocean Science 6, 219-234.

Steele, M., Morley, R., Ermold, W., 2001. Phc: A global ocean hydrography with a high quality Arctic Ocean. J. Climate 14, 2079-2087.

de Steur, L., Hansen, E., Gerdes, R., Karcher, M., Fahrbach, E., Holfort, J., 2009. Freshwater fluxes in the east greenland current: A decade of observations. Geophysical Research Letters 36, L23611.

de Steur, L., Hansen, E., Mauritzen, C., Beszczynska-Möller, A., Fahrbach, E., 2014.

Impact of recirculation on the East Greenland Current in Fram Strait: Results from moored current meter measurements between 1997 and 2009. Deep Sea Research Part I: Oceanographic Research Papers 92, 26 - 40.

Wadley, M.R., Bigg, G.R., 2002. Impact of flow through the Canadian Archipelago and Bering Strait on the north Atlantic and Arctic circulation: An ocean modelling study. Quarterly Journal of the Royal Meteorological Society 128, 2187-2203.

Wang, Q., Ilicak, M., Gerdes, R., Drange, H., Aksenov, Y., Bailey, D., Bentsen, M., Biastoch, A., Bozec, A., Böning, C., Cassou, C., Chassignet, E., Coward, A., Curry, B., Danabasoglu, G., Danilov, S., Fernandez, E., Fogli, P., Fujii, Y., Griffies, S., Iovino, D., Jahn, A., Jung, T., Large, W., Lee, C., Lique, C., Lu, J., Masina, S., Nurser, A., Rabe, B., Roth, C., Salas y Mélia, D., Samuels, B., Spence, P., Tsujino, H., Valcke, S., Voldoire, A., Wang, X., Yeager, S., 2015. An assessment of the Arctic Ocean in a suite of interannual CORE-II simulations. Part I: Sea ice and solid freshwater. Ocean Modell. , under revision. 
Wekerle, C., Wang, Q., Danilov, S., Jung, T., Schröter, J., 2013. The canadian arctic archipelago throughflow in a multiresolution global model: Model assessment and the driving mechanism of interannual variability. J. Geophys. Res. - Oceans 118, 4525-4541.

Woodgate, R.A., Aagaard, K., 2005. Revising the Bering Strait freshwater flux into the Arctic Ocean. Geophysical Research Letters 32, L02602.

Woodgate, R.A., Aagaard, K., Weingartner, T.J., 2005. Monthly temperature, salinity, and transport variability of the Bering Strait through flow. Geophysical Research Letters 32, L04601.

Woodgate, R.A., Aagaard, K., Weingartner, T.J., 2006. Interannual changes in the Bering Strait fluxes of volume, heat and freshwater between 1991 and 2004. Geophysical Research Letters 33, L15609.

Woodgate, R.A., Weingartner, T.J., Lindsay, R., 2012. Observed increases in Bering Strait oceanic fluxes from the Pacific to the Arctic from 2001 to 2011 and their impacts on the Arctic Ocean water column. Geophysical Research Letters 39, L24603. 